\title{
Wage Posting and Business Cycles: a Quantitative Exploration*
}

\author{
Giuseppe Moscarini ${ }^{\dagger}$ \\ Yale University \\ and \\ NBER
}

\author{
Fabien Postel-Vinay \\ University College London \\ and \\ Sciences Po
}

Final: November 2015

\begin{abstract}
We provide a quantitative exploration of business cycles in a frictional labor market under contract-posting. The steady-state random search and wage-posting model of Burdett and Mortensen (1998) has become the canonical structural framework for empirical analysis of worker turnover and equilibrium wage dispersion. In this paper, we provide an efficient algorithm to simulate a dynamic stochastic equilibrium version of this model, the Stochastic Burdett-Mortensen model, and evaluate its performance against empirical evidence on fluctuations in unemployment, vacancies and wages.
\end{abstract}

Keywords: Equilibrium Job Search, Dynamic Contracts, Stochastic Dynamics, Business Cycles.

JEL codes: J64, J31, E32.

*The authors thank Melvyn Coles and two anonymous referees for very useful comments. Moscarini thanks the NSF for support to this research under grant SES 1123021

†Address: Department of Economics, Yale University, PO Box 208268, New Haven CT 06520-8268. Tel. +1-203-432-3596. E-mail giuseppe.moscarini@yale.edu. Web http://www.econ.yale.edu/faculty1/moscarini.htm.

$\ddagger$ Address: Department of Economics, University College London, Drayton House, 30 Gordon Street, London WC1H 0AX, UK. Tel: +44 117928 8431. E-mail fabien.postelvinay@gmail.com. Web https://sites.google.com/site/fabienpostelvinay/. Postel-Vinay is also affiliated with the Centre for Macroeconomics (CfM, London), CEPR (London) and IZA (Bonn). 


\section{Introduction}

Why are similar workers paid differently? In his 2003 book of this title, Dale Mortensen (Mortensen (2003)) takes stock of a few decades of investigation of this question, that he had jumpstarted and then developed. His answer is simple: imperfect competition in labor markets. Information and other frictions, which make the outcome of job search timeconsuming and random, endow firms with monopsony power that they exploit, in the spirit of Coase (1972), by committing to wage offers. This force depresses all wages towards the opportunity cost of work. But workers cannot commit to their current terms of employment and, while employed, search for better outside offers. In this environment, firms choose a wage policy that balances labor costs with hiring and retention. As a result, in equilibrium, wages must differ among identical firms and workers. In the presence of heterogeneity in productivity and in demand conditions among workers and firms, equilibrium wages still fall short of marginal products, and contain a non-fundamental component of "frictional" inequality. If workers could freely reallocate across heterogeneous firms, they would arbitrage away any wage differences.

Burdett and Mortensen (1998) formalized this powerful insight. Their working paper, first circulated in the 1980s, spurred the vast theoretical and empirical literature culminating in Dale Mortensen's 2003 book. The Burdett and Mortensen (1998) "wage posting" model quickly emerged as the canonical framework for the analysis of wage inequality, labor turnover, and unemployment. Each of the three exists in conjunction with the other two. Naturally, the scope of this line of research eventually transcended wage inequality alone.

In a series of articles ((Moscarini and Postel-Vinay, 2009, 2012, 2013, Forthcoming)) we explored, both theoretically and empirically, the business cycle implications of the wage posting paradigm. Progress in this direction had been stunted by technical difficulties in finding equilibrium in an economy where the law of one price fails. The other canonical model of the labor market now known as "DMP" (Diamond (1982); Pissarides (1985); Mortensen and Pissarides (1994)) bypassed this hurdle by assuming that trading partners bargain over their match surplus, which takes any allocative role away from wages. The DMP model still encodes the leading theory of equilibrium unemployment, but runs into difficulties when applied to business cycles. As Shimer (2005) demonstrated, this model cannot reconcile the large cyclical swings in job finding and unemployment rates with the tiny ones in Average Labor Productivity (ALP) that we observe in the US economy. The perfectly competitive labor market model had failed this test, because it required an implausibly elastic aggregate labor supply. The same issue came back to haunt the search-cum-bargaining model Hagedorn and Manovskii (2008). The attention then turned to other sources of am- 
plification. We add to this range of new hypotheses. The simple Coasian assumption of commitment to wage offers to exploit market power, here conferred by frictions and tempered by on-the-job search, is a natural source of wage rigidity, in an environment that can also explain wage inequality and reallocation and that is very well understood in steady state since Burdett and Mortensen (1998).

In our past theoretical work, we outlined the scope and limitations of wage posting models with random search in the presence of aggregate shocks to labor productivity. Our main empirical focus was on the cyclical reallocation of employment among heterogenous firms (Moscarini and Postel-Vinav (2012)). Our contribution here is to evaluate the quantitative performance of our Moscarini and Postel-Vinay (2013) business cycle wage-posting model against empirical evidence regarding not only wage inequality and the pace of reallocation, as is standard in this approach, but also business cycle fluctuations in unemployment and wages. To this end, we propose a tractable, stochastic equilibrium version of the Burdett and Mortensen (1998) model — we will refer to is as the "Stochastic BM" (SBM) model — and an operational algorithm to simulate its equilibrium.

Different varieties of wage-posting models with on-the-job search introduced aggregate shocks and maintained tractability by making one key change to the environment. Menzio and Shi (2011) assume perfect information about posted wages, in the tradition of directed or competitive search, and study business cycle movements in labor market quantities, but not in wages. Closer to our exercise, Robin (2011) maintains random search, but relaxes the full commitment and equal treatment assumptions, to adopt Postel-Vinay and Robin (2002)'s sequential auctions, in which firms can respond individually to outside offers received by their employees. This change greatly simplifies the analysis of business cycles. Robin addresses empirical evidence on both labor market flows and wages. Relative to these two contributions, in our SBM model computation of equilibrium wages is less straightforward. However, we show that it is still feasible, and we propose a reasonably fast algorithm to achieve this end. We build on the simple structure of the stochastic equilibrium, which is Rank-Preserving, as first defined in Moscarini and Postel-Vinay (2009): more productive and larger firms always offer higher values to all workers, independently of the history of aggregate shocks. Thus, workers always move in the same direction between jobs: given the distribution of firm recruiting effort, equilibrium turnover is trivial to simulate and generates empirically accurate predictions about job ladder movements over business cycles (Moscarini and Postel-Vinay (Forthcoming)). Our more demanding task now is to compute the equilibrium recruiting policies and contracts (or state-contingent wages) that implement this equilibrium allocation.

The broader goal of this project is to provide a unified explanation, based on a stochastic 
job ladder, for worker turnover and individual earnings dynamics, residual wage inequality unexplained by worker characteristics, and business cycle fluctuations in unemployment and average earnings. This is a very ambitious goal. In this first quantitative step, to give our model a reasonable chance to perform well over business cycles, we introduce a seemingly minor but important change relative to Moscarini and Postel-Vinav (2013). Following Pissarides (2009)'s suggestion, we model adjustment frictions on the firm side as a cost that depends on the volume of hires and not, as is customary, of vacancies or job adverts. Search for trading partners is still mediated by a matching function, but the firm pays for the output of its recruiting activities, not for the inputs into it. As such, hiring costs are best thought of as training costs. This feature of the model tames congestion effects that facilitate hiring in recessions, when unemployment is abundant, and thus mute the negative impact of aggregate shocks on job creation (see Christiano et al. (2013)). This change in the model requires a new argument to prove that equilibrium retains the RP property, essential for tractability. We find that this property requires a restriction on the convexity of the hiring/training cost function 1

We gauge the quantitative performance of our SBM model along three main dimensions. First, we assess the model's ability to amplify TFP shocks, based on its predictions about the volatility and covariances of unemployment, the job finding rate and the vacancyunemployment $(V / U)$ ratio, in the face of TFP shocks of a plausible magnitude. Second, we examine wage flexibility in the model, as measured by the earnings-unemployment semielasticity (on which we provide new evidence from the Survey of Income and Program Participation — SIPP), and the time-series volatility of mean log earnings. Third, we reexamine the Burdett and Mortensen (1998) model's predictions about cross-sectional dispersion in wages, profits, and employer sizes - the focus of many analyses of the steady-state Burdett and Mortensen (1998) model. In so doing, we highlight new connections between the model's cross-sectional and business-cycle predictions.

Our summary assessment of the successes and failures of this SBM model is as follows. A clear success of the SBM model is its ability to generate plausible amplification of TFP shocks. For example, the predicted volatility ratio of the job finding rate relative to ALP, which has been the focus of much attention in the literature, can be as high as 15, well in line with the data. Yet, wages in the SBM model are much more flexible than they appear to be in the data: the model-based wage-unemployment semi-elasticity is up to ten times larger than the one we estimate from SIPP data. How, then, does the model generate plausible

\footnotetext{
${ }^{1}$ Coles and Mortensen (2011) adopt a hiring cost function and impose on it even more structure, as explained in Footnote [4, to extend the scope of our early work on transitional dynamics (Moscarini and Postel-Vinav (2009)). They establish existence and characterization of one RP equilibrium also in the presence of idiosyncratic, firm-level TFP shocks.
} 
amplification? First, even though wages are very flexible, the values that workers care about and, ultimately, matter for the allocation are much stickier. Second, and most importantly, the model generates amplification by concentrating hiring amongst firms at the bottom of the productivity ladder. Those low-productivity firms generate a low surplus, so that even with flexible wages, small fluctuations in productivity cause large (proportional) variations in profitability, and consequently on hiring, for those firms (as per the intuition put forward in a different context by Hagedorn and Manovskii (2008) and revisited by Ljungqvist and Sargent $(2015))$.

This amplification mechanism highlights a trade-off between aggregate volatility of unemployment and cross-sectional dispersion in employer size. We achieve concentration of hiring at low-productivity firms by assuming a very highly convex recruitment (or training) cost function. This strong degree of diminishing returns to hiring tames the incentives of highly-productive firms to hire much more than low-productivity firms. Dispersion in gross hiring flows between high- and low- productivity firms is therefore very small and, as a consequence, so is dispersion in equilibrium size between firms. The largest firm in the simulated economy is only about four times the size of the smallest one, in constrast to millions observed in the data. This tension between size dispersion and amplification is arguably the key link between the model's cross-sectional and dynamic predictions.

Next, the SBM model tends to understate cross-sectional wage dispersion. This is not a new finding: as pointed out by Hornstein et al. (2011), if the residual wage dispersion observed in US data was truly the result of search frictions, a jobless worker searching for jobs should wait to sample a high paying job. But average unemployment duration in the U.S., as measured in the Current Population Survey, is short 2 On-the-job search helps to resolve this tension, at least qualitatively, because accepting quickly a low offer does not 'burn' all of the option value of looking for a better wage. The SBM model generates up to two thirds of the residual dispersion in monthly earnings estimated from the SIPP, under a reasonable calibration of the value of leisure and of measurement error in earnings. So, while not a complete success, our exercise goes a long way towards addressing the Hornstein et al. (2011) critique.

Finally, as we highlighted in previous work (Moscarini and Postel-Vinav (2013)), the model offers a natural explanation for our observation (Moscarini and Postel-Vinav (2012)) that net job creation is more negatively correlated with aggregate unemployment at large

\footnotetext{
${ }^{2}$ Using data from the Survey of Income and Program participation (SIPP), Fujita and Moscarini (2013) show that unemployment duration in the US is shortest for the large share of workers who end up being recalled by their former employers, and is in fact much longer than commonly thought, even in good times, for those unemployed workers who are hired by new employers, which is presumably what search models are really about. The CPS does not contain information to make this distinction.
} 
than at small firms. In the SBM model this still holds, although, as mentioned, exactly the opposite is true of gross job creation, which is the source of aggregate volatility in job finding rates. Intuitively, in an aggregate expansion, small employers hire proportionally more new workers than, but lose even more employees to poaching by, larger competitors, so their employment grows more slowly on net. The opposite occurs in recessions, the Great Recession being a perfect example (Moscarini and Postel-Vinay (Forthcoming)) 3 The disconnect in the model between the cyclicality of gross and net job creation among heterogeneous firms is critical. Bils et al. (2012) show, in a DMP-style model, that a similar tension between aggregate volatility and cross-sectional inequality on the worker side cannot be resolved. They observe that the importance of small surplus emphasized by Hagedorn and Manovskii (2008) applies to the labor supply of the marginal, not the average, worker. Hence, they ask whether worker ex ante skill heterogeneity can amplify the effect of aggregate shocks on the average job finding rate, by concentrating job finding volatility among low-skill individuals, whose surplus from work over leisure is small. They show that this is indeed the case only if the calibrated model also delivers job finding rates for high wage workers that are far too sticky relative to the data. Just like large, productive firms exhibit surprisingly cyclical net job creation rates, so high-wage, productive workers face surprisingly cyclical exit rates from unemployment. In our exercise, the distinction between gross and net flow, which exists for an individual firm but not an individual worker, resolves this tension.

The rest of the paper is organized as follows. Section 2 introduces the SBM model and establishes conditions for equilibrium to be RP, hence computable. Our quantitative analysis follows in Section [3, which presents empirical moments upon which the calibration and simulation presented in Section 4 are based. After some concluding remarks, the Appendix contains the proofs of the formal arguments and presents the structure of the computation algorithm.

\section{A wage-posting model of the business cycle}

\subsection{The environment}

Our Stochastic Burdett and Mortensen (1998) (SBM) model is a variant of Moscarini and Postel-Vinay (2013)'s business cycle model of a frictional labor market with random search and wage posting. In this version, we introduce firm-level hiring costs that depend on the output of the hiring process, namely on the flow of hires, rather than on the input, vacancies or job ads. So hiring costs are best thought of as a combination of search and training costs. As empha-

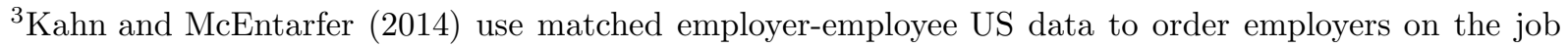
ladder by the average wage they pay, and find direct evidence for this cyclical poaching pattern.
} 
sized by Pissarides (2009), hiring costs are independent of competition in the market, hence, unlike vacancy costs, they do not fall in recessions, when labor demand is lower, and do not mute the effect of aggregate shocks 4

Time $t=0,1,2 \ldots$ is discrete. The labor market is populated by a unit-mass of ex ante homogeneous workers, who can be either employed or unemployed, and by a unit measure of ex ante heterogeneous firms, which can be either active in production or idle. Workers and firms are risk neutral, infinitely lived, and maximize payoffs discounted with common factor $\beta \in[0,1)$. Firms operate constant-return technologies with labor as the only input and with productivity scale $\omega_{t} p$, where $\omega_{t} \in \Omega$ is an aggregate component, evolving according to a stationary first-order Markov process $Q\left(d \omega_{t+1} \mid \omega_{t}\right)$, and $p$ is a fixed, firm-specific component, distributed across firms $p$ according to a c.d.f. $\Gamma$ over some positive interval $[\underline{p}, \bar{p}]$.

The labor market is affected by search frictions in that unemployed workers can only sample job offers sequentially with some probability $\lambda_{t} \in(0,1]$ at time $t$ and, while searching, enjoy a value of leisure $b_{t}$. Employed workers earn a wage and also sample job offers with probability $s \lambda_{t} \in(0,1]$ each period, so that $s$ is the search intensity of employed relative to unemployed job seekers. Workers receive at most one job offer per time period. Each employed worker is separated from his employer and enters unemployment every period with probability $\delta_{t} \in(0,1]$. All firms of equal productivity $p$ start out with the same labor force $L_{0}(p)$. We denote by $L_{t}(p)$ the size of a firm of type $p$ at time $t$ on the equilibrium path, and $N_{t}(p)=\int_{\underline{p}}^{p} L_{t}(x) d \Gamma(x)$ the cumulated population distribution of employment across firm types. So $N_{0}(\bar{p})$ is the (given) initial measure of employment at firms of productivity at most $p, N_{t}(\bar{p})$ is employment and $u_{t}=1-N_{t}(\bar{p})$ the unemployment (rate) at time $t$.

We maintain throughout the assumption that the destruction rate is exogenous and a function of the aggregate productivity state $\delta_{t}=\delta\left(\omega_{t}\right)$. Similarly for the flow value of non production $b_{t}=b\left(\omega_{t}\right)$. The job-contact probability $\lambda_{t}$ instead is determined in equilibrium by a matching function. Each period, the firm can hire $h$ workers at cost $c(h)$, with $c(\cdot)$ positive, strictly increasing and convex, continuously differentiable. To do so, before workers have a chance to search, a firm can post $a \geq 0$ job adverts (vacancies). Own job adverts determine the firm's sampling weight in workers' job search, while total job adverts determine the rate at which any one advert returns contacts with workers. Let $a_{t}(p)$ denote the adverts posted on the equilibrium path by a firm of productivity $p$ and size $L_{t-1}(p)$, and define aggregate

\footnotetext{
${ }^{4}$ This assumption is taken up in a growing number of contributions to the topic at hand, including the closely related paper by Coles and Mortensen (2011). In their paper, recruitment costs are specified as $L c(h / L)$, where $L$ is initial firm size and $h$ is the inflow of new hires, so that $h / L$ is the number of new hires per incumbent worker in the firm.
} 
adverts $A_{t}$ and aggregate search effort by workers $Z_{t}$ as

$$
\begin{aligned}
& A_{t}=\int_{\underline{p}}^{\bar{p}} a_{t}(p) d \Gamma(p) \\
& Z_{t}=1-N_{t-1}(\bar{p})+\left(1-\delta_{t}\right) s N_{t-1}(\bar{p}) .
\end{aligned}
$$

The latter adds the previously unemployed to the previously employed who are not displaced, weighted by their search intensity $s$. In each time period, employed and unemployed search simultaneously. Then:

$$
\eta_{t} A_{t}=\lambda_{t} Z_{t}=m\left(A_{t}, Z_{t}\right) \leq \min \left\langle A_{t}, Z_{t}\right\rangle
$$

where $\eta_{t}$ is the chance for any advert to contact a worker, $m(\cdot)$ is a linearly homogeneous matching function, increasing and concave in each argument.

The timing within a period is as follows. Given a current state $\omega_{t}$ of aggregate labor productivity and distribution of employed workers $N_{t}$ :

1. firms produce and sell output and pay workers in state $\omega_{t}$; the flow benefit $b_{t}$ accrues to unemployed workers;

2. the new state $\omega_{t+1}$ of aggregate labor productivity is realized;

3. employed workers can quit to unemployment;

4. filled jobs are destroyed exogenously with chance $\delta_{t+1}$;

5. firms post job adverts $a_{t+1}$;

6. the remaining employed workers receive an outside offer with chance $s \lambda_{t+1}$ and decide whether to accept it or to stay with the current employer; simultaneously, each previously unemployed worker receives an offer with probability $\lambda_{t+1}$;

7. firms hire workers and pay hiring costs that depend on how many workers they hire.

Finally, in order to avert unnecessary complications, we assume that the state space $\Omega$ is finite, the distribution of firm types, $\Gamma$, has continuous and everywhere strictly positive density $\gamma=\Gamma^{\prime}$ over $[\underline{p}, \bar{p}]$, and the initial measure of employment across firm types, $N_{0}$, is continuously differentiable in $p$. 


\subsection{The firm's contract-posting and hiring problem}

Each firm of any type $p$ chooses and commits to an employment contract, namely a wage $w_{t}(p)$ contingent on state variables to be specified, to maximize the present discounted value of profits at time 0 , given other firms' contract offers. The dependence of the wage on the state is marked for now as a shorthand by the time index of the wage. The firm is further subjected to an equal treatment constraint, whereby it must pay the same wage to all its workers. Under commitment, such a wage function implies an equilibrium value $V_{t}(p)$ for any worker to work for that firm.

We introduce some notation. Let

$$
F_{t}(W)=\frac{1}{A_{t}} \int_{\underline{p}}^{\bar{p}} \mathbb{I}\left\{V_{t}(p) \leq W\right\} a_{t}(p) d \Gamma(p)
$$

(where $\mathbb{I}\{\cdot\}$ is the indicator function) denote the c.d.f. of values posted by all firms and offered to searching workers, with $\bar{F}_{t}(\cdot)=1-F_{t}(\cdot)$, i.e. $F_{t}$ is the distribution of values from which job searchers draw from,

$$
G_{t}(W)=\frac{1}{N_{t-1}(\bar{p})} \cdot \int_{\underline{p}}^{\bar{p}} \mathbb{I}\left\{V_{t}(p) \leq W\right\} d N_{t-1}(p)
$$

denote the c.d.f. of values accruing to the currently employed workers. Note that $G_{t}$ depends on the distribution of employment $N_{t-1}$ at the end of period $t-1$, i.e. the beginning of period $t$, as $N_{t}$ is determined by $G_{t}$ itself at the end of the period. Let

$$
U_{t}=b_{t}+\beta \mathbf{E}_{t}\left[\left(1-\lambda_{t+1}\right) U_{t+1}+\lambda_{t+1} \int \max \left\langle v, U_{t+1}\right\rangle d F_{t+1}(v)\right]
$$

be the value of unemployment. The unemployed worker collects a flow value $b_{t}$ and, next period, when aggregate productivity becomes $\omega_{t+1}$, she draws with chance $\lambda_{t+1}$ a job offer from the distribution of offered values $F_{t+1}$, that she accepts if its value exceeds that of staying unemployed. Each firm now has a sampling weight in $F_{t+1}$ equal to its (normalized) job posting, $a_{t+1} / A_{t+1}$.

A firm that observes state $\omega_{t+1}$ and decides to post a continuation value $W_{t+1}<U_{t+1}$ loses all workers, who quit to unemployment, so $L_{t+1}=0$. In that case, the firm exits, at least temporarily. Because it cannot be optimal to let all workers go and then hire identical workers back in the same period, this firm posts no job ads, $a_{t+1}=0$, and contributes nothing to the sampling distribution $F_{t+1}$. For the same reason, no worker earns less than $U_{t}$, or $G_{t}\left(U_{t}-\right)=0$. Conversely, a firm of current size $L_{t}$ posting any value $W_{t+1} \geq U_{t+1}$ loses workers to unemployment, with chance $\delta_{t+1}$, and to other firms, if its workers draw offers, 
with chance $s \lambda_{t+1}$, which are more valuable, with chance $\bar{F}_{t+1}\left(W_{t+1}\right)$. The firm chooses to hire $h_{t+1}$ workers. Formally:

$$
L_{t+1}=L_{t}\left(1-\delta_{t+1}\right)\left(1-s \lambda_{t+1} \bar{F}_{t+1}\left(W_{t+1}\right)\right)+h_{t+1}
$$

where hires $h_{t+1}=a_{t+1} \eta_{t+1} P_{t+1}\left(W_{t+1}\right)$ equals the measure of vacancies posted $a_{t+1}$ times the contact rate of each vacancy $\eta_{t+1}$ times the probability that the offer is accepted:

$$
P_{t+1}\left(W_{t+1}\right)=\frac{1-N_{t}(\bar{p})+s\left(1-\delta_{t+1}\right) N_{t}(\bar{p}) G_{t+1}\left(W_{t+1}\right)}{Z_{t+1}}
$$

In (44), the denominator is the measure of workers who can make contact, and the numerator counts only those who accept the offer, namely all the unemployed and only the fraction of employed who will earn less than $W_{t+1}$ by staying where they are.

Three of the payoff-relevant state variables of the firm's problem are aggregate and exogenous to the firm. Those are (1) aggregate productivity $\omega_{t},(2)$ the distribution of values offered by all firms $F_{t}$, and (3) the cross-section distribution of values earned by currently employed workers $G_{t}$. The latter two are infinite-dimensional and determine the hiring and retention effects of posting a contract value. In turn, given knowledge of all firms' strategies, $N_{t-1}$ is sufficient to calculate $G_{t}$. Again, these three state variables, $\omega_{t}, F_{t}, N_{t-1}$ are aggregate and exogenous to the firm: for notational simplicity, we subsume the dependence on all three of firms' and workers' values into a time index.

The firm's problem can be formulated recursively (Spear and Srivastava (1987)) by introducing an additional, fictitious state variable, namely the continuation utility $\bar{V}$ that the firm promised at time $t-1$ to deliver to the worker from this period $t$ onwards. So the firm solves

$$
\Pi_{t}\left(\bar{V}, L_{t}\right)=\sup _{\substack{w_{t} \geq 0 \\ h_{t+1} \geq 0 \\ W_{t+1} \geq U_{t+1}}}\left\langle\left(\omega_{t} p-w_{t}\right) L_{t}+\beta \mathbf{E}_{t}\left[-c\left(h_{t+1}\right)+\Pi_{t+1}\left(W_{t+1}, L_{t+1}\right)\right]\right\rangle
$$

subject to the law of motion (3) of firm size and a Promise-Keeping (PK) constraint to deliver the promised $\bar{V}$ :

$$
\begin{aligned}
\bar{V}=w_{t}+\beta \mathbf{E}_{t}\left[\delta_{t+1} U_{t+1}+\left(1-\delta_{t+1}\right)\left(1-s \lambda_{t+1} \bar{F}_{t+1}\left(W_{t+1}\right)\right) W_{t+1}\right. & \\
& \left.+\left(1-\delta_{t+1}\right) s \lambda_{t+1} \int_{W_{t+1}}^{+\infty} v d F_{t+1}(v)\right] .
\end{aligned}
$$

Expectations are taken with respect to the future realization $\omega_{t+1}$ of aggregate productivity and offer distribution $F_{t+1}$, conditional on $\omega_{t}, F_{t}, N_{t-1}$. 
To characterize the best response contract, we first describe an equivalent unconstrained recursive formulation of the contract-posting problem. We define the joint value of the firm and its existing workers:

$$
S_{t}=\Pi_{t}+\bar{V} L_{t}
$$

Solving for the wage $w_{t}$ from (6) , replacing it into the firm's Bellman equation (5), and using (3) to replace the expression for $L_{t+1}$ into $S_{t+1}=\Pi_{t+1}+W_{t+1} L_{t+1}$ in each future state, the joint value function $S_{t}$ solves the unconstrained, recursive maximization of the joint value of the firm-worker collective:

$$
\begin{aligned}
& S_{t}\left(p, L_{t}\right)=\omega_{t} p L_{t}+\beta \mathbf{E}_{t}\left[\delta_{t+1} L_{t} U_{t+1}\right. \\
& \left.+\sup _{\substack{h_{t+1} \geq 0 \\
W_{t+1} \geq U_{t+1}}}\left\langle\left(1-\delta_{t+1}\right) s \lambda_{t+1} L_{t} \int_{W_{t+1}}^{+\infty} v d F_{t+1}(v)-c\left(h_{t+1}\right)+S_{t+1}\left(p, L_{t+1}\right)-W_{t+1} h_{t+1}\right\rangle\right]
\end{aligned}
$$

The joint value $S_{t}$ to the firm of type $p$ and to its existing $L_{t}$ employees depends on these two and on aggregate state variables subsumed in the time index. This joint value equals flow output, $\omega_{t} p L_{t}$, plus the discounted expected continuation value. The latter includes (in order) the value of unemployment for those employees who are displaced exogenously, the value of a new job for those who are not displaced and find a better offer than the one extended by the current firm, minus the cost of hiring new workers, and, on the second line, the joint continuation value of the firm and of its current (time $t$ ) employees. In turn, the latter equals the joint continuation value $S_{t+1}$ of the firm and its future workforce - made up of stayers among the current (date- $t$ ) workforce plus next-period (date- $t+1)$ hires minus the value to be paid to new hires, either from unemployment or from other firms 5 The optimal policy solving the unconstrained DP problem (7) also solves (5) subject to (6). We therefore focus on the analysis of the simpler problem (7). We restrict attention to Markov equilibria, where the value offered by each firm depends exclusively on payoff-relevant variables, and not directly on the history of play.

Definition 1 A Markov (COntract-Posting) EQuilibrium is a pair of measurable functions $(V, H)$ of firm-specific productivity $p$, firm size L, aggregate productivity $\omega$, and aggregate distribution of employment $N$ such that, for every firm type $p$, if all other firms of type

\footnotetext{
${ }^{5}$ If we did not subtract this cost of employing new hires, this Bellman equation would generate the joint value of the firm and all of its workers, current and future. If this were the object maximized by the firm, it would optimally offer its workers the maximum value, i.e. pay a wage equal to productivity (the proof, omitted, is available upon request). As is standard, the efficient solution to a moral hazard problem is to "sell the firm to the workers". In our economy, however, firms do not pursue efficiency, but maximize profits. Therefore, the optimal value-offer policy is an interior solution.
} 
$x$ play $(V, H)$ so that (11), (2) and (3) hold with $W_{t}=V_{t}(x)$ where $V_{t}(x)=V\left(x, L_{t-1}(x), \omega_{t}, N_{t-1}\right)$ and $h_{t}=H_{t}(x)$ where $H_{t}(x)=H\left(x, L_{t-1}(x), \omega_{t}, N_{t-1}\right)$, the value-posting function $V_{t}(p)$, the wage function that implements it (i.e. solves ([6) with $\bar{V}=V_{t}(p)$ ) and the hiring function $H_{t}(p)$ are the optimal policies of the contracting problem (5).

An equilibrium is a fixed point, a solution $(V, H)$ to this DP problem that coincides with the strategy followed by the other firms. The reason why Markov strategies do not depend on the offer distribution $F_{t}$, given the employment distribution $N_{t-1}$, is simple. Given the equilibrium value-offer strategy $V$ and the employment distribution $N_{t-1}$, any firm of type

$p$ can compute for every competitor $x$ the probability $G_{t}\left(V_{t}(x)\right)$ from (2) and thus the acceptance probability $P_{t}\left(V_{t}(x)\right)$ from (4). Given the equilibrium hiring strategy $H$, firm $p$ can then derive the required vacancy posting $a_{t}(x)=H_{t}(x) / \eta_{t} P_{t}\left(V_{t}(x)\right)$ of any other firms $x$. Finally, $F_{t}$ derives from (11). So knowledge of equilibrium strategies (a requirement of Nash equilibrium) and of the employment distribution $N_{t-1}$ suffice to characterize all other infinite-dimensional state variables.

\subsection{Rank-Preserving Equilibrium (RPE)}

\subsubsection{Definition of RPE}

The main difficulty in characterizing equilibrium in Burdett and Mortensen (1998)'s environment in the presence of aggregate uncertainty, which hampered progress of this approach in the analysis of business cycles, is now clear. The distributions of values offered $F_{t}$ and earned $G_{t}$ are relevant to the firm maximization problem, because they determine the retention rate $F_{t}(W)$ of the firm's employees who are offered a contract of value $W$, and the poaching rate from other firms. This is a defining property of a random search, wage posting model. Even in the simpler Markov equilibrium the employment distribution $N_{t-1}$ at the end of the previous period is a state variable of the firm problem. Although the firm does not directly control them, it must still keep track of stochastically and endogenously evolving distributions, an infinitely complex problem.

An even simpler class of Markov equilibria circumvents this hurdle.

Definition 2 A RANK-PRESERving Equilibrium (RPE) is a Markov equilibrium such that, on the equilibrium path, a more productive firm always offers its workers a higher continuation value: $V_{t}(p)=V\left(p, L_{t-1}(p), \omega_{t}, N_{t-1}\right)$ is increasing in $p$, including the effect of $p$ on firm size $L_{t-1}(p)$.

As a direct consequence of the above definition, in a RPE, workers rank their preferences to work for different firms according to firm productivity at all dates. The RP property 
holds in the unique steady-state equilibrium characterized by Burdett and Mortensen (1998). Definition 2 proposes to extend it to a dynamic stochastic equilibrium with endogenous hiring.

\subsubsection{A characterization result}

The key contribution of Moscarini and Postel-Vinay (2013) is the proof that, in Burdett and Mortensen (1998)'s original environment with exogenous (but stochastic) contact rates, any Markov equilibrium must be Rank-Preserving under some restrictions on firm entry (see below), and under the weak sufficient condition that more productive firms start weakly larger at time 0. Thus, for any history of realizations of aggregate shocks, more productive and larger firms always offer their workers a higher value, which is the only available tool to control both hiring and retention. Therefore, the size ranking of firms is preserved over time: if $L_{t}(p) \geq L_{t}\left(p^{\prime}\right)$ for $p>p^{\prime}$ at date $t$, then $L_{t+1}(p)>L_{t+1}\left(p^{\prime}\right)$. Thus, by induction, $L_{t+n}(p)>L_{t+n}\left(p^{\prime}\right)$ for all positive integers $n$ : if a more productive firm is ever larger, it will remain larger for ever no matter what happens to aggregate productivity, because it will always offer a higher value to retain its workers and hire more workers. Furthermore, the equilibrium evolution of the employment distribution is the same in any RPE, so it is uniquely pinned down, and can be calculated independently of equilibrium contracts.

In this paper, we add a hiring choice $h$ to the firm's problem. The RP property alone therefore no longer suffices to ensure that more productive firms also hire more and, consequently, always remain larger. Offering a higher value only guarantees a better retention of existing employees, a reduction in the outflow, but firm size also depends on the gross hiring inflow $h$. Therefore, the conditions for the unique equilibrium of any kind to be RP, as in Moscarini and Postel-Vinay (2013), are slightly stronger, and the argument for the preservation of size ranking is not as straightforward. Yet we show in the following proposition that this property continues to hold in that case.

Proposition 1 (RPE with Hiring Costs) Assume that the hiring cost function $c(\cdot)$ is $\mathscr{C}^{2}$, with $c^{\prime}(h)>0$ for all $h>0$. Then any Markov contract-posting Equilibrium such that the sampling c.d.f. $F_{t}(\cdot)$ is everywhere differentiable at all dates $t$ is Rank-Preserving if:

1. more productive firms are weakly larger at the initial date, i.e. $L_{0}(p)$ is non-decreasing

2. $h c^{\prime \prime}(h) / c^{\prime}(h) \geq 1$, i.e. the elasticity of the marginal hiring cost $c^{\prime}(\cdot)$ is everywhere larger than 1 .

In any such $R P E$, size ranking is preserved at all dates: $L_{t}(\cdot)$ is non-decreasing at all $t$. 
Proof. See Appendix A.

Proposition 1 extends the characterization result of Moscarini and Postel-Vinav (2013) to the case of endogenous hiring, where firms face recruitment costs that are a function of their gross hiring inflow. It states sufficient conditions for any Markov equilibrium of our model to be RP 6 This simple equilibrium allows for cyclical entry and exit "at the bottom". Because the offered value is increasing in $p$, and must exceed the value of unemployment $U_{t}$ for the firm to be active, there exists a cutoff productivity such that only firms (if any) below that cutoff will be idle in each period. This cutoff varies with the aggregate productivity state, thus generating flctuations in entry and exit.

Condition 2 in Proposition 1, which requires that the training cost function be sufficiently convex, is a new requirement compared to the result in Moscarini and Postel-Vinay (2013). We will return to this condition in Section 4 below. Apart from that, Condition 1 was already present — and discussed - in Moscarini and Postel-Vinay (2013). This is a genuine restriction for a RPE. However, it is merely a sufficient condition: it aligns two separate motives to pay workers more, firm productivity and size, so there is some slack. Moreover, as explained in Moscarini and Postel-Vinay (2013), it is a property that arises "naturally" in the Burdett and Mortensen (1998) model, insofar as the steady-state distribution of firm sizes in the Burdett and Mortensen (1998) model satisfies it. As mentioned, the model can generate cyclical firm entry. Entry of firms "in the middle" of the productivity distribution, however, is ruled out as inconsistent with RPE: profitable business opportunities may arise and cause entry of highly productive firms, which by definition start out with a size of zero and are therefore likely to "break ranks" (see Moscarini and Postel-Vinay (2013) for an extended discussion).

With exogenous hiring policies, as we showed in Moscarini and Postel-Vinav (2013), the equilibrium allocation, or evolution of the firm size distribution, is uniquely determined, independently of the specific value strategies (wage contracts) that implement it, and is simple to compute. In Moscarini and Postel-Vinay (2013) we provide sufficient conditions for uniqueness also of RPE contracts, hence of Markov equilibrium, in the exogenous contact rate model. Our focus here is on computation of one equilibrium. We leave the question of uniqueness of equilibrium allocations and contracts in this hiring cost model for future research.

\footnotetext{
${ }^{6}$ The restriction to differentiable sampling c.d.f.'s simplifies the proof, but we suspect it is inessential - it is not imposed in Moscarini and Postel-Vinay (2013).
} 


\subsubsection{Some useful properties of RPE}

Three properties thus hold true in any RPE. First, the share of firms that offer less than $V_{t}(p)$ is simply the proportion of firms that are less productive than $p$ weighted by their relative vacancy postings

$$
F_{t}\left(V_{t}(p)\right)=\frac{1}{A_{t}} \int_{\underline{p}}^{p} a_{t}(x) d \Gamma(x) .
$$

Second, the share of employed workers who earn a value that is lower than that offered by $p$ equals the share of employment at firms less productive than $p$ :

$$
G_{t}\left(V_{t}(p)\right)=\frac{N_{t-1}(p)}{N_{t-1}(\bar{p})} .
$$

Third, the probability that an offer is accepted equals

$$
P_{t}\left(V_{t}(p)\right)=\frac{1-N_{t-1}(\bar{p})+s\left(1-\delta_{t}\right) N_{t-1}(p)}{1-N_{t-1}(\bar{p})+s\left(1-\delta_{t}\right) N_{t-1}(\bar{p})}:=Y_{t}(p) .
$$

Therefore the sampling weight is $a_{t}(p)=H_{t}(p) /\left(\eta_{t} Y_{t}(p)\right)$, and we can write it as a function of the chosen hiring flow. As we will see shortly, these restrictions drastically simplify the computation of equilibrium in the stochastic model.

In Moscarini and Postel-Vinav (2013) we further establish that on the RPE path the joint value $S_{t}(p, L)$ of a firm of type $p$ and of its $L$ employees is differentiable in $L$. Our focus in this paper being on computation, we restrict attention to differentiable equilibria without

formally extending Moscarini and Postel-Vinav (2013)'s differentiability proof to the case of endogenous hiring. We define the costate variable

$$
\mu_{t}(p)=\frac{\partial S_{t}}{\partial L}(p, L(p))
$$

which is the shadow marginal value of an additional worker to the firm-employees collective. Using the RP implications (8) and (9) in the Bellman equation (17), differentiating the latter on both sides with respect to $L_{t}$, and invoking the Envelope theorem:

$$
\begin{aligned}
\mu_{t}(p)=\omega_{t} p+\beta \mathbf{E}_{t}\left[\delta_{t+1} U_{t+1}+\left(1-\delta_{t+1}\right)\right. & \left(1-\frac{s \lambda_{t+1}}{A_{t+1}} \int_{p}^{\bar{p}} a_{t+1}(x) d \Gamma(x)\right) \mu_{t+1}(p) \\
& \left.+\left(1-\delta_{t+1}\right) \frac{s \lambda_{t+1}}{A_{t+1}} \int_{p}^{\bar{p}} a_{t+1}(x) V_{t+1}(x) d \Gamma(x)\right]
\end{aligned}
$$

where in the last integral we changed variable from value $V \sim F_{t}$ to productivity $p \sim \Gamma$.

The equilibrium policies $V_{t}(p)$ and $H_{t}(p)$ solve the NFOCs for the maximization of (7):

$$
\begin{array}{ll}
{[W]:} & H_{t}(p)=\left[\mu_{t}(p)-V_{t}(p)\right]\left(1-\delta_{t}\right) s \lambda_{t} L_{t-1} f_{t}\left(V_{t}(p)\right) \\
{[h]:} & c^{\prime}\left(H_{t}(p)\right)=\mu_{t}(p)-V_{t}(p) .
\end{array}
$$


Next, noticing that (8) implies

$$
f_{t}\left(V_{t}(p)\right)=\frac{d F_{t}\left(V_{t}(p)\right)}{d V_{t}(p)}=\frac{d F_{t}\left(V_{t}(p)\right)}{d p} \frac{1}{V_{t}^{\prime}(p)}=\frac{a_{t}(p)}{A_{t}} \frac{\gamma(p)}{V_{t}^{\prime}(p)}
$$

we can rewrite the FOC for $W$ as

$$
H_{t}(p)=\left[\mu_{t}(p)-V_{t}(p)\right]\left(1-\delta_{t}\right) s \lambda_{t} L_{t-1}(p) \frac{a_{t}(p)}{A_{t}} \frac{\gamma(p)}{V_{t}^{\prime}(p)}
$$

Together with the law of motion of employment, equations (10), (111) and (12) are the backbone of an algorithm to describe the evolution of the equilibrium of this economy subject to aggregate shocks. The algorithm computes an approximation to the equilibrium contract in which each firm, while still viewing aggregate productivity $\omega_{t+1}$ as random and taking the conditional expectation in (10) w.r.t. this random variable, evaluates the future marginal value of a new employee $\mu_{t+1}(p)$ in the r.h.s. of (10) as if the period- $t$ realized employment distribution $N_{t}$ were always the one occurring on the equilibrium path $N_{t}^{\star}$, regardless of $\omega_{t}$. That firms make this approximation is common knowledge (so each firm knows that other firms do so, and computes accordingly the distribution of offers made by competitors). Moreover, firms understand that the period- $t$ employment distribution $N_{t}$ indeed varies with $\omega_{t}$ and use the correct period- $t$ employment distribution that occurs in each aggregate state $\omega_{t}$ in the computation of the conditional expectation in (10), except for the evaluation of $\mu_{t+1}(p)$. The quality of the numerical approximation rests on the twofold observation that the employment distribution, in the data as well as in our calibration of exact RPE dynamics, moves slowly, and that the marginal value of a worker $\mu_{t}(p)$ is much more responsive to variations in $\omega_{t}$ than to variations in the other aggregate state variable, $N_{t-1}$. We provide the details of this algorithm in Appendix B.

\section{Data}

\subsection{Labor market and productivity}

Most of the aggregate time series that we exploit to either calibrate or test the model are available at monthly frequency. Nonetheless, we sample and filter them at quarterly frequency, because Total Factor Productivity (TFP) and Average Labor Productivity (ALP) series are available only quarterly. To maintain consistency with these data, we calibrate and simulate the model at monthly frequency, then aggregate its output to quarterly frequency.

The unemployment rate is the civilian unemployment rate of the US population aged 16 and up from the BLS, starting in 1948:Q1 through 2015:Q1. We calculate transition

rates between labor market states Employment (E) and Unemployment (U), using stocks 
of $\mathrm{E}$ and $\mathrm{U}$ and flows EU and UE from monthly CPS matched files (BLS "Research series on labor force status flows from the CPS") beginning in 1990:Q1, through 2014:Q4. We do not use unemployment-duration based measures, nor do we correct for time aggregation (Shimer (2012)), and we treat any short spell of unemployment that completes within a month, and is missed by monthly CPS interviews, as a continuous employment spell. We make the latter choice for two reasons: the model is calibrated monthly, so workers there have no chance to make more than one transition per month, and in the data a majority of very short unemployment spells end in recall by the same employer (Fujita and Moscarini $(2013))$.

The $V / U$ ratio is the ratio between the JOLTS vacancy rate (currently available for 2010:Q4-2015:Q2) for the US private nonfarm sector and the civilian unemployment rate.7

For TFP we use quarterly estimates of the Solow residual by Fernald (2012), and for ALP we take Output per job in the Nonfarm business sector from the BLS (series PRS85006163), both in 1948:Q1-2015:Q1.

We log and HP-filter all quarterly time series, labor market stocks and flows with parameter 100,000, productivity series with parameter 1,600. We then compute second moments for all observations up to 2012:Q4 included, excluding 2013-2015 to avoid end-of-period HP filtering bias, although this makes little difference. Although the vacancy and worker flow series are available for a much shorter time span than the rest, we use all the available data to filter each series and, except for the last two years, to compute volatilities and correlations. We prefer to take this approach rather than to shorten our sample to the longest period when they are all available, but we should keep in mind that some second moments refer to shorter subperiods than others.

We report in Table 3, in rows indicated by (D) for Data, standard deviations (last number on each row) and correlation coefficients of the filtered components of each series. In addition to the numbers report in Table 3, the data tell us that (detrended log) TFP has a volatility of .0127 (about the same as ALP — see Table 3), and correlation - 0.4 with detrended $\log$ unemployment. Finally, the first-order serial correlation of $\log$-TFP is 0.78. Based on this, we remark that TFP and ALP have similar volatilities, an order of magnitude smaller than that of the (log) unemployment rate, but TFP, unlike ALP, has a strong negative correlation with the unemployment rate. This reflects in part the fact that our filtered ALP measure turned slightly countercyclical since the 1980s.

\footnotetext{
${ }^{7}$ This ratio is routinely referred to as labor market tightness in the context of the DMP model. However, the relevant concept of market tightness in our model, which features on-the-job search, is not the $V / U$ ratio: rather, it is the ratio of vacancies to total worker search effort, $U+s(1-\delta)(1-U)$. Because the $V / U$ ratio has been the focus of much attention in the literature, we report statistics pertaining to that variable, even though it does not have a straightforward interpretation within the context of our model.
} 


\begin{tabular}{|c|c|c|c|c|}
\hline \multirow[t]{2}{*}{ log earnings } & \multicolumn{2}{|c|}{ "monthly } & \multicolumn{2}{|c|}{ "quarterly } \\
\hline & (1) & $(2)$ & $(3)$ & $(4)$ \\
\hline unemployment rate & $\begin{array}{c}-.60 \\
(.11)\end{array}$ & $\begin{array}{c}-.50 \\
(.11)\end{array}$ & $\begin{array}{c}-.58 \\
(.11)\end{array}$ & $\begin{array}{c}-.49 \\
(.11)\end{array}$ \\
\hline 25-99 employees & & $\begin{array}{l}065 \\
.004)\end{array}$ & & $\begin{array}{l}.062 \\
. .004)\end{array}$ \\
\hline 100+ employees & & $\begin{array}{r}.078 \\
.005)\end{array}$ & & $\begin{array}{r}.075 \\
(.005)\end{array}$ \\
\hline observations $(i, t)$ & \multicolumn{2}{|c|}{$2,910,524$} & \multicolumn{2}{|c|}{986,149} \\
\hline workers $(i)$ & \multicolumn{2}{|c|}{82,036} & \multicolumn{2}{|c|}{81,457} \\
\hline $\operatorname{Var}_{i t}($ errors $)$ & .18 & .18 & .16 & .16 \\
\hline$R^{2}$ & .22 & .23 & .23 & .24 \\
\hline
\end{tabular}

Notes: Source: SIPP. Monthly unemployment rate is HP-filtered with parameter $10^{5}$. Quarterly $\log$ earnings and unemployment rate are averages of monthly series. Robust standard errors in parentheses. All specifications include quartic time trend and demographic controls.

Table 1: Fixed-effect regression of individual real log earnings

\section{$3.2 \quad$ Wages}

We use the 1996, 2000, 2004 and 2008 panels of the Survey of Income and Program Participation (SIPP). This is a collection of panels of workers, on average about 40,000 workers per panel. Each worker is surveyed every four months about events that occurred over the past four months ('wave'). Workers are assigned to rotation groups: in each calendar month, roughly one quarter of the panel completes a wave and is re-interviewed. The SIPP has significant longitudinal and time dimensions, provides information about a large number of individual outcomes, and is nationally representative.

As the model has no intensive margin of labor supply, for our measure of wages we take monthly earnings (TPMSUM), which are also less contaminated by measurement error than hourly pay rates, especially those constructed as the ratio of earnings to "usual hours worked per month". We deflate earnings with monthly CPI and take logs. A "seam bias" arises from a tendency of SIPP respondents to bunch reported changes in earnings and labor market status around interview times. Rotation groups are staggered, however, so seams are evenly distributed over time. The only exceptions are the first four and last three months of each panel, when no rotation group has a seam, but excluding those months has little impact on the results.

We aim to extract information about the cyclical component of earnings for comparable workers, as our model has homogeneous workers. To this purpose, we run, with both monthly and quarterly data, a fixed effect regression of individual real log earnings, constructed as described above, on the detrended unemployment rate, a common linear trend, a cubic in age, 
and dummies for the four available worker characteristics that may change over time: class of worker (private, government, non-profit etc.), education (17 categories), marital status and union coverage. In columns 2 and 4 of Table 1 we also control for a coarse measure of employer size available in the SIPP data 8 Race, gender and any other time-invariant worker characteristics are absorbed by the individual fixed effect. The regression uses the SIPP longitudinal weights to maintain the representative character of the sample.

The results in Table 1 indicate a negative wage-unemployment semi-elasticity, significant at conventional levels. Looking at columns 2 and 4, we see that employer size comes out positive and significant, as predicted by the theory. The addition of employer size in the set of regressors reduces (the point estimate of) the unemployment semi-elasticity of wages somewhat, due to a composition effect, also consistent with the theory: periods of low (high) unemployment are periods in which the workforce is more concentrated among higher-paying and larger (lower-paying and smaller) employers (we return to this point in the next section). The first row of Table1, specifically column 3, provides our empirical target for the cyclicality of wages produced by the model. The bottom of the table presents our empirical target for the residual wage variance, to be explained by the model as frictional inequality.

\section{Calibration and simulation}

In order to gauge the business cycle properties of the model, we begin with a detailed analysis of a baseline calibration, which is designed to maximize the model's ability to replicate the observed levels of cylical volatility in unemployment and in the job finding rate. Attaining this goal requires a few "unconventional" choices of parameter values. We subsequently assess the model's performance under more conventional parameterizations.

\subsection{Baseline calibration}

We specify the aggregate shock process as a discrete 20-state first-order Markov chain that approximates a monthly $\mathrm{AR}(1)$ process for $\ln \omega$. The AR coefficient (0.94) and the variance of innovations (0.006) are set such that the model replicates the observed variance and firstorder autocorrelation of HP-detrended output per worker 9

The job destruction rate is allowed to fluctuate deterministically with $\omega$ as follows:

$$
\delta(\omega)=0.0114+1.894 \times\left(\ln \omega_{\max }-\ln \omega\right)^{2.5}
$$

\footnotetext{
${ }^{8}$ This measure is an indicator of whether the worker's current employer has payroll of up to 24 , between 25 and 99, or 100 workers and above at the time of interview.

${ }^{9}$ Output per worker does not exactly coincide with $\omega$ in the model because of the gradual selection of workers up the job ladder, but it turns out to be very close.
} 


\begin{tabular}{lr}
\hline \hline firm type distribution: & $\Gamma(p)=\frac{1-p^{-2.5}}{1-\bar{p}^{-2.5}, \text { with }[\underline{p}, \bar{p}]=[1,10]}$ \\
monthly discount factor: & $\beta=0.95^{1 / 12}$ \\
employed search intensity: & $s=0.13$ \\
matching function: & $m(A, Z)=A$ \\
hiring cost: & $c(h)=(44 \times h)^{50} / 50$ \\
unemployment income: & $b=0$ \\
\hline \hline
\end{tabular}

Table 2: Baseline calibration

where the intercept, slope and exponents in this definition are chosen to approximate the mean, standard deviation, (positive) skewness and kurtosis of the observed EU rate.

All other parameter values and functional form assumptions are summarized in Table 2. The distribution of firm types is a truncated Pareto distribution, with the top firm being 10 times as productive as the worst one that could ever operate in the economy. The discount factor is the monthly equivalent of a $5 \%$ discount rate per annum. The employed search intensity $s$ is set to match an average monthly EE transition rate of around $1.2 \%$, in line with SIPP data.10 The matching function is simply a linear function of the aggregate number of job adverts. This differs from the more commonly used Cobb-Douglas specification with a vacancy elasticity of 0.5 , and as such calls for some comments. First, there is some evidence that the estimated vacancy elasticity of the matching function is substantially higher than 0.5 when employed job seekers are counted as inputs into the matching process Petrongolo and Pissarides (2001) 11 Second, the standard procedure in the empirical literature that produced this "standard value" of 0.5 for the matching function elasticity consists of running an OLS regression of the log of the job finding rate on the log of the $V / U$ ratio; when we do the same on simulated series from our model, we obtain a "matching function elasticity" of 0.47 , well within the range of standard estimates.

The hiring (training) cost function is iso-elastic, and highly convex. The need for a highly convex hiring cost function is suggested by the sufficient condition stated in Proposition 1 . In the simulation, more convex hiring costs tend to increase the volatility of the job finding rate, for reasons discussed below in Paragraph 4.2.4. The scaling factor in the hiring cost

\footnotetext{
${ }^{10}$ There are many different ways to define EE transitions in the SIPP (or any other) data. Here we allow for up to seven days of non-employment between jobs, and up to a month for "voluntary" EE transitions, i.e. when respondents stated that they quit their past job to take another one. Adding "involuntary" EE transitions (in the form of forced job-to-job reallocations, as for instance in Jolivet et al. (2006)) would be a straightforward extension.

${ }^{11}$ Even when on-the-job search is ignored, recent estimates by Borowczyk-Martins et al. (2013) that account for the endogeneity of vacancies in the presence of reallocation shocks suggest that the matching function elasticity may be higher than commonly assumed, in the region of 0.8 .
} 
function is set so that the average job finding rate is in line with the data, given that the "TFP" of the matching function was normalized to one.

Finally, the unemployment flow income $b$ is set equal to 0 . Low estimates of $b$ are common in empirical applications of Burdett and Mortensen (1998)-type models, for the reasons discussed in Hornstein et al. (2011), and are sometimes justified by appealing to a disutility, or "stigma", attached to the state of unemployment which has to be subtracted from what is literally income in the flow value of unemployment. Here, however, we adopt this low value of $b$ in the baseline calibration for a very different reason, which is to avoid entry and exit: a high value of $b$ would induce some low-productivity firms to shut down in bad aggregate states, and re-enter in good ones. The additional effect of firm entry and exit on the model's predictions is explored below under some of the alternative calibrations, where we raise the value of $b$. As we will see, this has little impact on residual wage inequality, so the job ladder overcome the force towards wage compression highlighted by Hornstein et al. (2011).

More generally, as mentioned, this baseline calibration involves some unconventional parameter values. Those include the flow income in unemployment, but also the matching function elasticity and the degree of convexity of the training cost. We revisit those values below in Sub-section 4.3. First, we discuss the output of our baseline calibration.

\subsection{Main quantitative results and model fit}

We simulate the model over a window of 70 years (a length comparable to the times series described in Section [3) using the algorithm described in Appendix B. We now discuss various aspects of the fit and some predictions of the model.

\subsubsection{Labor market variables and ALP}

Table 3 reports, as already discussed, the data moments (D), together with their model counterparts (M) 12

The model captures well the facts that unemployment, the job finding rate from it, and, slightly less well, the $V / U$ ratio are an order of magnitude more volatile than ALP. This demonstrates the model's potential to generate a plausible level of amplification of TFP shocks. The model also replicates the correlations between the various labor market indicators, despite a tendency to understate the correlations between the EU separation rate and the unemployment and job finding rates. Overall, though, the model comes close enough

\footnotetext{
${ }^{12}$ The quarterly autocorrelation of detrended ALP, not shown in the tables, is 0.77 in the data and 0.78 in the simulation.
} 


\begin{tabular}{lc|ccccc}
\hline \hline & & U rate & UE rate & EU rate & $V / U$ & ALP \\
\hline U rate & $(\mathrm{D})$ & .216 & & & & \\
& $(\mathrm{M})$ & .201 & & & & \\
\multirow{4}{*}{ UE rate } & $(\mathrm{D})$ & -.974 & .121 & & & \\
& $(\mathrm{M})$ & -.987 & .130 & & & \\
& $(\mathrm{D})$ & .889 & -.887 & .114 & & \\
$V / U$ & $(\mathrm{M})$ & .783 & -.682 & .115 & & \\
& $(\mathrm{D})$ & -.978 & .972 & -.912 & .366 & \\
\multirow{4}{*}{$\mathrm{ALP}$} & $(\mathrm{M})$ & -.998 & .994 & -.752 & .279 & \\
& $(\mathrm{D})$ & .108 & -.017 & -.275 & -.011 & .013 \\
\hline \hline & $(\mathrm{M})$ & -.715 & .627 & -.885 & .686 & .014 \\
\hline
\end{tabular}

Table 3: Fit to correlations and standard deviations of quarterly cyclical components

to replicating the moments relating to labor market variables, including the volatility of the job finding rate, which has been the focus of attention in much of the recent literature.

Where the model does poorly is in predicting the correlations between ALP and the various labor market indicators. This, however, is hardly surprising in a model where the only impulse driving aggregate fluctuations is a TFP shock. Allowing for additional uncorrelated shocks is likely to raise the volatility of the job finding rate in the model, decoupling labor market indicators from ALP13

\subsubsection{Wages}

We construct a model-predicted semi-elasticity of wages (real monthly earnings) to the unemployment rate by running a weighted OLS regression of firm-level log wages on a constant and on the detrended unemployment rate, with weights equal to $L_{t}(p) \gamma(p)$. This is the closest we can get, using the model, to the worker-level regressions reported in Table 1. The predicted semi-elasticity thus computed (at quarterly frequency) is -7.90 . Comparison of this number with the value of -0.6 reported in the last column of Table 1 suggests that wages are much more procyclical in the model than in the data. The predicted semi-elasticity drops a little to -6.97 when firm size is included among the covariates in the aforementioned regression. While this drop parallels the drop seen between columns 3 and 4 of Table 1, the predicted semi-elasticity is still far too large.

As another point of comparison, the quarterly unit labor cost series produced by the BLS over the period 1947-2013 has a cyclical volatility of 0.016 (after taking logs and HP-filtering

\footnotetext{
${ }^{13}$ Shocks to the matching technology or to the job destruction rate come to mind as natural candidates. A recent papers by Hall (2014) makes a case for a countercyclical discount factor.
} 
with parameter 1,600$)$. The model counterpart of this number is 0.065 , further corroborating the conclusion that predicted mean wages are too cyclical. Although wages in the model are allocative, they merely serve to implement worker values that drive the allocation of employment in the model. Worker values are more informative than wages in this model. Their standard deviation is 0.035 at quarterly frequency, and their unemployment semielasticity is -2.07 . Worker values are thus substantially less volatile than wages in the model: forward-looking values anticipate future mean-reversion in wages, and smooth wage fluctuations. In fact, the mechanism is best understood in reverse. Job creation depends on the firms' present value of profits, the difference between output streams and values paid to workers. In order for profits to be sufficiently procyclical to generate the desired volatility in job finding rates, worker values must be relatively smooth, but not completely acyclical. Wages have to respond strongly to aggregate shocks in order to generate some movement in those forward-looking values.

The literature pointed at excess wage volatility to understand the failure of Nash bargaining models to generate much amplification of TFP shocks. But Ljungqvist and Sargent (2015), elaborating on Hagedorn and Manovskii (2008), argue that the responsiveness of wages to TFP shocks is in fact not necessary for amplification, and emphasize the size of the surplus of matches. This theme emerges also here.

As discussed in the Introduction, one of the key contributions of our SBM model is that it generates endogenous cross-sectional wage dispersion and as such makes predictions on second- and higher-order moments of the wage distribution. Focusing on cross-sectional wage dispersion, the pooled cross-section wage variance predicted by the model is 0.08 . This falls far short of the residual variance of 0.18 found in the SIPP data and reported in Table 1. Some of that 0.18 variance is arguably attributable to measurement error. Lemieux (2006) reports a share of around a third, based on CPS data on wage rates. Applied here, this share would imply a genuine residual log earnings variance of 0.12 in the SIPP. While our model's 0.08 still falls short even of this target, it makes very significant progress. The failure to replicate the observed amount of residual wage dispersion - at least under "standard" parameterizations — is a well-known and recurring problem of wage posting models (see Hornstein et al. (2011), and the discussion in our Introduction), from which our SBM dynamic contract posting model is not immune. On the job search, however, goes a long way towards resolving this conundrum. Davis and von Wachter (2012), using the DMP model with a job ladder proposed by Burgess and Turon (2010), conclude that on the job search falls far short of this task. Our contract-posting model does much better. One reason is that workers moving from job to job compare values, not wages, and values are much more compressed than wages (as mentioned, standard deviation 0.035, or variance 0.0012). 


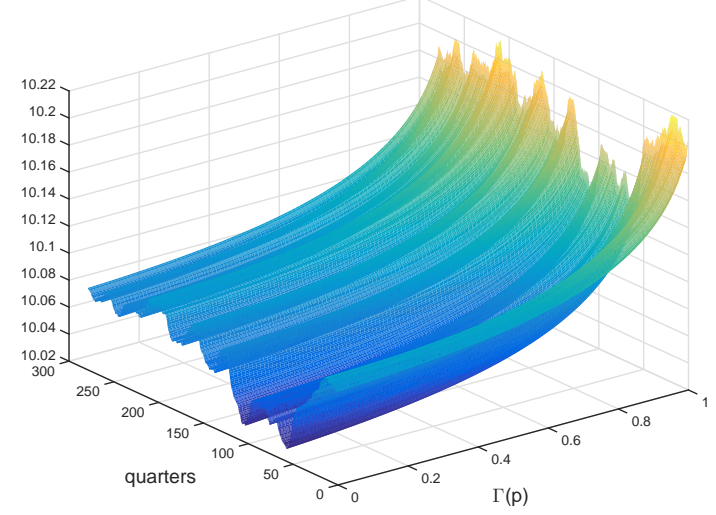

(a) Worker values

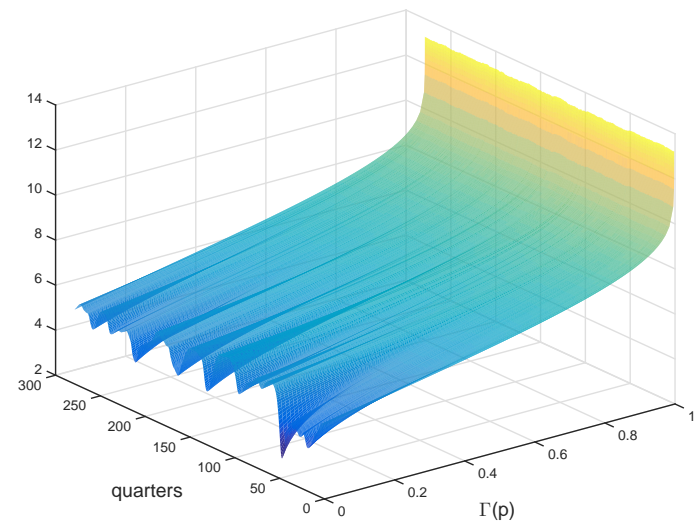

(b) Profits

Fig. 1: Marginal profits and worker values over time

In turn, this occurs because even values offered by low-productivity firms contain the option value of climbing to more productive firms.

Finally, we can address the cyclical behavior of wage inequality. A number of recent papers have documented the fact that idiosyncratic wage risk, broadly defined as the crosssectional standard deviation of wage growth, is countercyclical (Storesletten et al. (2004)). The predicted correlation between the cross-section standard deviation of log wage growth and the (detrended) unemployment rate is 0.23 .14 The model thus replicates, at least qualitatively, the counter-cyclicality of wage risk found in the data.

\subsubsection{Profits and worker values}

Figure 1a plots the profile of $(\log )$ values posted by each firm, $\ln V_{t}(p)$, as a function of the quantiles of $p$ in the distribution $\Gamma$, over time. Figure $1 \mathrm{~b}$ does the same for the (log) profitability of the marginal job in any given firm type, $\ln \left[\mu_{t}(p)-V_{t}(p)\right]$. As per the properties of RPE, $V_{t}(p)$ is increasing in $p$ at all dates. Figure $1 \mathrm{~b}$ suggests that this is also the case for marginal profitability, although this result is not guaranteed in theory.

A closer look at Figure 1b further reveals that job profitability is much more cyclically sensitive at low-productivity firms than at the top end of the productivity distribution. This is because jobs at low-productivity firms generate smaller surplus than jobs at highproductivity firms, and their value is therefore more elastic to TFP shocks. Interestingly, Figure 1a suggests that this difference in cyclicality across firm types is not passed on to worker values. This is because these values account for the possibility of moving down the ladder, where profits are volatile, and are also driven by very volatile job finding rates.

\footnotetext{
${ }^{14}$ The model-predicted standard deviation of wage growth is constructed by taking the standard deviation of firm-level wages weighted by initial employment at each firm. Thus, by design, it measures the wage risk faced by job stayers.
} 


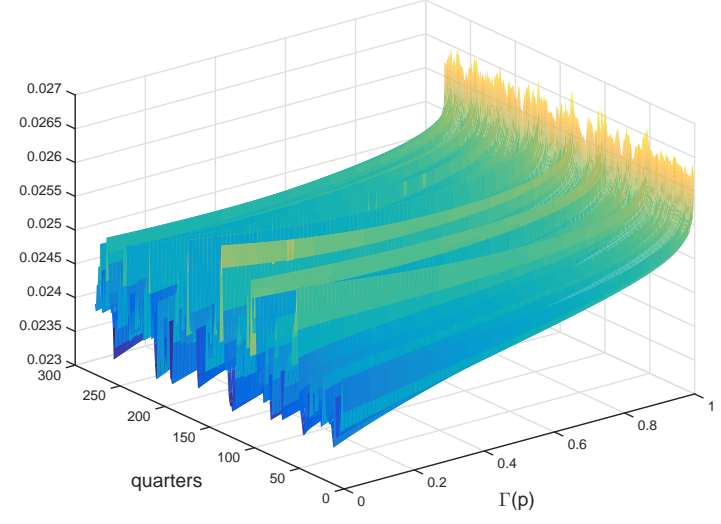

(a) Hires

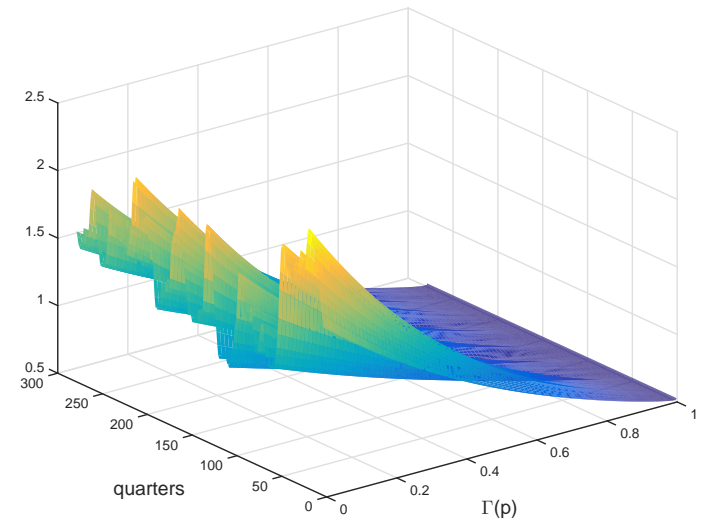

(b) Job adverts

Fig. 2: Firm-level job adverts and hiring flows over time

\subsubsection{Job adverts, hiring flows, and firm size}

Proposition 1 states that in RPE, a firm that is more productive and initially larger than another stays larger period after period. But it says nothing about whether more productive firms actually hire more or merely retain a larger fraction of their initial workforce by posting more attractive job values. Figure 2 provides an answer. Figure 2 a plots the profile of firm-level hiring flows, $H_{t}(p)$ (still as functions of the quantiles of $p$ in the distribution $\Gamma)$ over time, while Figure $2 \mathrm{~b}$ plots the profile of firm-level job adverts, $a_{t}(p)$. It appears that $H_{t}(p)$ is mostly, although not always strictly increasing in $p$, while $a_{t}(p)$ is decreasing: more productive firms tend to hire a larger inflow of workers at most dates, but manage to do so by spending less effort on hiring, simply through the fact that they offer more attractive job values, thus enjoying a higher job-ad yield. Figure 2 further shows that job adverts, and therefore hires, are much more cyclically sensitive at low-productivity than at high-productivity firms, echoing the similar remark made above about profitability of the marginal job. The firm's hiring decision is indeed governed by the FOC (11), which imposes equality between the cost of the marginal hire $\left(c^{\prime}(h)\right.$, an increasing function of $\left.h\right)$, and its profitability, $\mu(p)-V(p)$.

Another remarkable feature of Figure $2 \mathrm{a}$ is the lack of dispersion in the level of gross hiring inflows across firm types. On average over the simulated sample, the most productive firm in the market only hires $12.5 \%$ more workers per quarter than the least productive one. This is in spite of a 10-fold difference in productivity between the highest- and lowestproductivity employer in this economy. As a further consequence, the model vastly underpredicts dispersion in firm sizes: the predicted size ratio between the smallest and largest employer in the economy is 4.24 on average, nowhere near the levels observed in the data.

The reason for this lack of dispersion in employer size and hiring inflow is the very high 
degree of convexity of the hiring cost function $c(\cdot)$. As mentioned Sub-section 4.1, this high degree of convexity is needed for the model to amplify TFP shocks to the extent observed in the data. In that sense, the model faces a tradeoff between time-series volatility and crosssectional dispersion. As seen on Figures 1 and 2, profitability and (consequently) hiring and job-ad posting are much more volatile at low-productivity than at high-productivity firms, as the former generate a much smaller surplus than the latter. In order to inflate the volatility of aggregate job adverts, the model needs to concentrate hiring among lowproductivity firms. The highly convex training cost does exactly that: it curtails hiring at high- $p$ firms, which are much more profitable than low- $p$ firms but face prohibitive marginal training costs beyond a modest level of hiring.

\subsubsection{The Beveridge curve}

Figure 3 shows two different versions of the Beveridge curve produced by the model. The blue plot is the "empirical Beveridge curve", or $V U$-curve, i.e. a plot of the unemployment rate against aggregate job adverts. While this $V U$-curve makes no particular sense in a model with on-the-job search, it is interesting for being an object of keen empirical investigation, and the basis for most of the existing inference on matching functions. The red plot on Figure 3 is the Beveridge curve that is consistent with our model, i.e. a plot of aggregate worker search effort, $1-N_{t}(\bar{p})+s\left(1-\delta_{t}\right) N_{t}(\bar{p})$, against aggregate job adverts 15

Both versions of the Beveridge curve look as they should, downward sloping and convex, despite a perfectly countercyclical job destruction rate. Interestingly, however, the "empirical" Beveridge curve is slightly flatter than the "consistent" one. In other words, if one were to use any of these plots for prediction, one might conclude that a decrease in labor market tightness by a given amount will cause a larger increase in the mass of job seekers, hence a larger drop in the job finding rate, under the empirical Beveridge curve than under the consistent one, which takes employed job seekers into account. This tallies with the remark made earlier, when discussing calibration: although the true matching function has a unit elasticity in the model, estimating a misspecified job finding rate based on the empirical version of the Beveridge curve - i.e. regressing this rate on the $V / U$ ratio - will understate the sensitivity of the job finding rate to changes in market tightness. The magnitude of the bias suggested by the model (estimated elasticity of 0.47 instead of 1 ) is quite remarkable. Where does the bias come from? The job finding rate is a function not of the $V / U$ ratio, but of labor market tightness which equals the ratio of aggregate job adverts (or vacancies) to aggregate job search effort, $1-N(\bar{p})+s(1-\delta) N(\bar{p})$, which accounts for the competition

\footnotetext{
${ }^{15}$ Aggregate worker search effort has been rescaled to produce Figure 3 , in such a way that both series on the $x$-axis of the figure have equal means.
} 


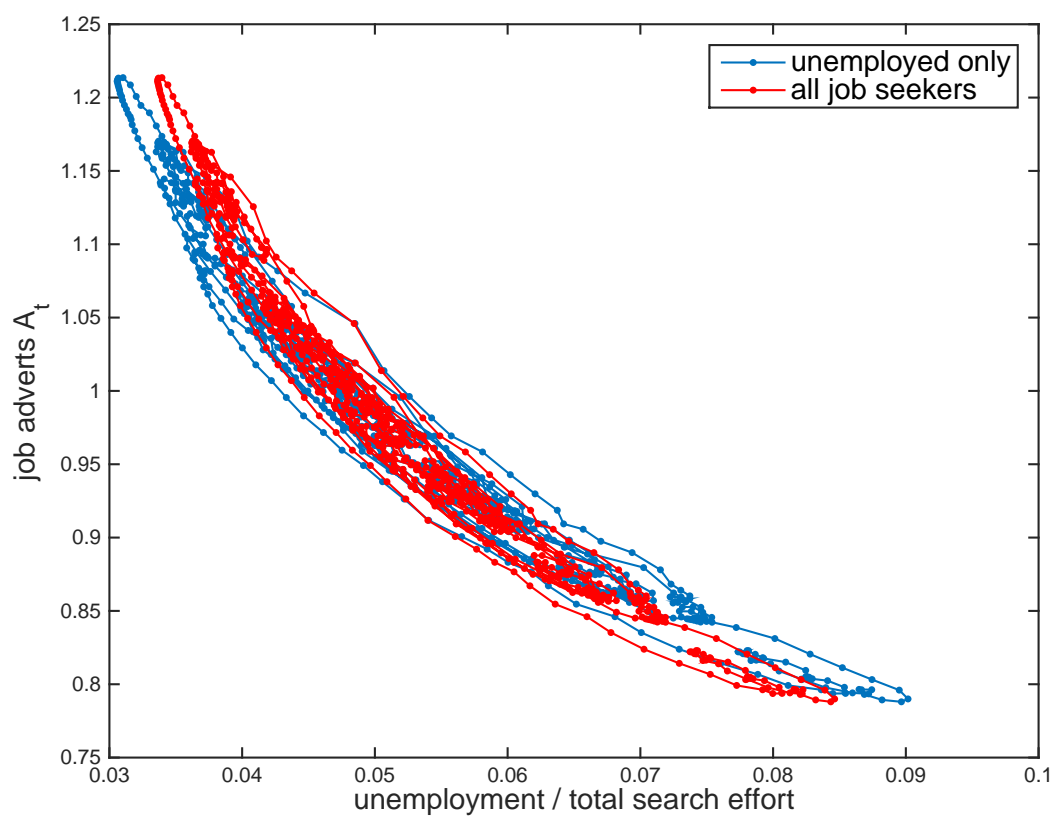

Fig. 3: The Beveridge curve

that unemployed workers face from employed job seekers. Because employed job seekers are fewer in recessions and more in expansions, actual tightness varies relatively less than the $V / U$ ratio over the cycle, which explains the lower estimated elasticity of the job finding rate to the $V / U$ ratio than to tightness.

\subsubsection{The cyclicality of net job creation}

As pointed out earlier, gross job creation is much more cyclical among small, low-productivity employers than at the top end of the productivity distribution. Yet in Moscarini and Postel-Vinay (2012) we highlight that, in US data, exactly the opposite is true of net job creation: as a group, small employers fare relatively better in bad times of high unemployment, and worse in good times of low unemployment. As we propose in other work (Moscarini and Postel-Vinay (2009), Moscarini and Postel-Vinay (Forthcoming)), this empirical pattern is qualitatively consistent with job ladder models, of which this paper offers a new example: in a tight labor market, high-paying, large employers overcome the scarcity of unemployed job applicants by poaching employees from smaller, less productive and lower-paying competitors, whose employment share then shrinks in relative terms. When the expansion ends, large employers, that were less constrained, have more employment to shed than small ones. In addition, the resulting high unemployment relaxes hiring constraints on all employers, particularly the small ones that are less capable of poaching from other firms. As a result, small employers downsize less in the recession and grow (relatively) faster in the recovery. 
This mechanism is at work here. To put a number on its magnitude, we construct series of total net job creation among two groups of firms, one at the top and one at the bottom of the productivity ladder, both classes being re-designed at each date so that they each have an employment share of $25 \%$. We then subtract net job creation in the group of low- $p$ firms from net job creation in the group of high- $p$ firms, and HP-detrend this difference to obtain a measure of relative net job creation similar to the series we analyzed in Moscarini and Postel-Vinay (2013). The correlation of this simulated series of relative net job creation with the simulated unemployment rate is -0.87 : as expected, the relative net job creation of large vs. small employers is procyclical. How plausible the magnitude of that predicted correlation is appears hard to assess, for lack of immediately comparable data. In Moscarini and Postel-Vinay (2013) we report numbers for U.S. data that vary between -0.25 and -0.6 , depending on the data set, period, sector, etc. Again, the correlation produced by the model is on the high side of that range, something that is to be expected as the outcome of a one-shock model.

As discussed in the Introduction, the disconnect between gross hires and net employment growth that exists at multi-worker firms is critical to understand our empirical observations, and model predictions: large, high-productivity firms have much more procyclical net employment growth than bottom firms, but much less procyclical gross hires, which are what matters for aggregate job finding rates. We conclude that the basic insight of Hagedorn and Manovskii (2008) applies to the bottom of the job ladder, where the surplus is small, and is sufficient to generate aggregate volatility if that bottom is sufficiently populated with firms. Conversely, the same principle does not work in a world of heterogeneous workers, as in Bils et al. (2012): although low-wage employees are a large share of employment, and enjoy small surplus over unemployment, high wage workers too have very volatile and procyclical employment rates. Our emphasis on ex-ante firm heterogeneity bypasses this hurdle.

\subsection{Alternative calibrations}

We end this section by illustrating the impact of some of the less conventional choices of parameter values featuring in our baseline calibration. We do so by running simulations under alternative values of the matching function elasticity, convexity of the training cost, and flow value of unemployment, as indicated in Table 4. For clarity, we implement those changes one parameter at a time. Results are gathered in Table 4 for a sample of statistics of interest. More complete results are available upon request. 


\begin{tabular}{lcccc}
\hline \hline & \multicolumn{4}{c}{ Calibration: } \\
\cline { 2 - 5 } & Baseline & $c(h)=\frac{(154 \times h)^{3}}{3}$ & $\begin{array}{c}m(A, Z) \\
=A^{0.5} Z^{0.5}\end{array}$ & $b=59.7$ \\
\hline Unemployment volatility & .201 & .105 & .175 & .190 \\
UE rate volatility & .130 & .037 & .088 & .165 \\
corr(UE,Unemployment) & -.985 & -.760 & -.991 & -.936 \\
Wage variance & .081 & .089 & .083 & .066 \\
Firm size range & $4.24: 1$ & $137.4: 1$ & $4.51: 1$ & $35.0: 1$ \\
\hline \hline
\end{tabular}

Table 4: Quantitative results under alternative calibrations

\subsubsection{The training cost function}

We first experiment with a less convex training cost function — specifically, we implement the cubic specification shown in Table 2, leaving all other parameters unchanged 16 As can be seen in the second column of Table 4, some of the hiring activity shifts from low- to high-productivity firms. As previously discussed, since the latter have higher surplus and less volatile profits than the former, this shift results in a much less volatile and much less cyclical aggregate job finding rate, and consequently a less volatile unemployment rate: with a cubic specification of the hiring cost function, the model predicts about half of the observed volatility of unemployment.

Yet, reflecting the trade-off between volatility and dispersion highlighted above, reducing the convexity of the hiring cost increases the dispersion in employer sizes substantially. The size ratio between the largest and smallest firm in the economy is now 137.4 on average. While this still falls short of observed magnitudes, it is considerably higher than the 4.24 ratio found under the baseline calibration. The cross-sectional dispersion of wages also increases as a result of the same composition effect. The predicted wage variance under this specific cubic specification is 0.089 , higher than in the baseline case.

\subsubsection{The matching function}

We next experiment with a matching function elasticity of 0.5 , which is arguably at the opposite extreme of the range of elasticities found in the literature compared to our baseline, linear-in-job postings specification. This change has remarkably little impact on the simulated statistics reported in Table 4; unemployment and the job finding rate are little less

\footnotetext{
${ }^{16}$ Note that the scaling factor in front of the training cost is also different from the baseline case: it was adjusted to produce a plausible average job finding rate.
} 
volatile, wages and employer sizes are marginally more dispersed than in the baseline case, but those differences are small and within the range of simulation noise.

Unsurprisingly, the difference between this and our baseline calibration is in the estimated matching function. While the true matching function elasticity is 0.5 , a regression of the job finding rate on the $V / U$ ratio (which, once again, replicates standard practice in matching function estimation) produces a coefficient of 0.29 , well below the range of published empirical results. This result motivates our choice of a linear matching function in the baseline calibration.

\subsubsection{The value of unemployment, firm entry and firm exit}

In our final calibration variant, we set the flow value of unemployment to $b=59.7$, equal across all aggregate states. This puts $b$ at about $50 \%$ of the mean wage in the economy. The main novelty under this alternative calibration is that entry and exit of firms now occurs at the low end of the productivity distribution: in times of relatively low aggregate productivity $\omega$, the marginally profitable firm type is in the interior of $[\underline{p}, \bar{p}]$, and fluctuates with $\omega .17$ As expected, the measure of active firms is procyclical in this model, with a correlation of -0.57 with unemployment at quarterly frequency. Looking at firm entry - i.e. the one-period change in the measure of active firms - reveals that entry leads unemployment by about four quarters. The correlation of unemployment and the four-quarter lag of the change in the measure of active firms is -0.19 , whereas the contemporaneous correlation between those two variables is a positive 0.16 .

Next turning to the results in Table 4, one sees that raising the value of unemployment has very little effect on the predicted amount of amplification. If anything, unemployment volatility is a little lower in this high- $b$ variant than in the baseline, $b=0$ case, but the difference is well within the range of simulation noise. This similarity, however, is the net result of two opposing forces. First, the main force generating amplification, namely the fact that job creation is concentrated at marginally profitable firms with low surplus, is still at work and even strenghened now: when unemployment income is high, the surplus of marginal firms, which are prone to entry and exit, is very close to zero - and in any case smaller than the surplus of low-productivity firms in the $b=0$ case, where even type- $\underline{p}$ firms make a positive surplus in all aggregate states. This makes the low-productivity end

\footnotetext{
${ }^{17}$ Allowing for entry and exit requires some additions to the algorithm described in Appendix B, In particular, the decision to enter or exit is based on total firm value $S\left(p, L_{t}(p)\right)$ (more precisely, a firm will exit in states where the continuation value in (7) falls short of the value of shutting down, i.e. $U_{t+1} L_{t}(p)$ ). The algorithm as described in Appendix Bonly computes the value $\mu_{t}(p)=\partial S\left(p, L_{t}(p)\right) / \partial L$ of the marginal worker in any given firm. Allowing for entry and exit thus requires the additional computation of $S\left(p, L_{t}(p)\right)$ along the equilibrium path. Details are available upon request.
} 
of the population of active firms more volatile in the high- $b$ than in the $b=0$ case and tends to further amplify TFP shocks. Yet, with a high $b$ causing entry and exit, those lowsurplus firms get weeded out in recessions, and only enter, with an initial workforce of zero, in good aggregate conditions. As a result, employment ends up being more concentrated at higher-surplus firms (firms with higher $p$ ) which survive recessions and maintain a positive workforce, even in bad times. It turns out that those two opposing effects have similar magnitudes in this calibration.

As could have been predicted based on the insight of Hornstein et al. (2011), a higher value of unemployment further reduces the amount of cross-sectional wage dispersion predicted by the model, which, however, remains sizable. Finally, the range of firm sizes is wider, again due to entry and exit of firms at the low end of the productivity scale. Those marginal firms see their workforce reset to zero each time they exit, and as a result stay very small on average over time.

\section{Concluding remarks}

The wage-posting model of the labor market with random search is one of the most influential and enduring contributions of Dale Mortensen and his students. The main goal of this paper is to show that this canonical model of the labor market naturally belongs in the toolbox of business cycle theorists. We study its quantitative performance and confront it with empirical evidence from the US. This is our first step in this direction and, as such, is truly exploratory in nature.

Our exercise reveals dimensions on which the model performs well, and also a fundamental tension between its predictions for aggregate volatility and for cross-sectional inequality in wages and firm size. We emphasize that this tension emerges precisely because the model is unusually equipped to address both sides of this trade-off, inequality and cyclical volatility. In this regard, the model generates business cycles of the correct magnitude by exploiting firm heterogeneity, in particular, the concentration of gross hires among unproductive, small, cyclically sensitive firms. This is more than offset by a strong cyclical response of job to job quits, so that net job creation is more volatile among large firms, a prediction that in previous work we argued to be shared by many job ladder models, and that we validated

empirically in Moscarini and Postel-Vinay (2013). We also find promise in the model's ability to generate cyclical comovement of the empirically correct sign between unemployment and wage levels, wage inequality, worker turnover. Much work lies ahead to identify suitable specifications and parameterizations of hiring costs, state-contingent contracts, search effort that may further improve the model's quantitative performance along these dimensions. 
We believe that additional insights from this stochastic job ladder model lie ahead. An especially promising direction is understanding individual earnings dynamics, the focus of the incomplete market literature, their relationship to labor market transitions, up and down the job ladder, and their cyclicality.

\section{References}

Bils, Mark, Yongsung Chang, and Sun-Bim Kim, "Comparative advantage and unemployment'," Journal of Monetary Economics, 2012, 59 (2), 150-165.

Borowczyk-Martins, Daniel, Gregory Jolivet, and Fabien Postel-Vinay, "Accounting for Endogeneity in Matching Function Estimation," Review of Economic Dynamics, 2013, 3 (16), 440-451.

Burdett, Kenneth and Dale T. Mortensen, "Wage Differentials, Employer Size and Unemployment," International Economic Review, 1998, 39, 257-73.

Burgess, Simon and Helene Turon, "Worker Flows, Job Flows and Unemployment in a Matching Model," European Economic Review, 2010, 54 (3), 393408.

Christiano, Larry, Marty Eichenbaum, and Mathias Trabandt, "Unemployment and Business Cycles," August 2013. NBER WP 19265.

Coase, Ronald, "Durability and Monopoly," Journal of Law and Economics, 1972, 15 (1), $143-49$.

Coles, Melvyn and Dale T. Mortensen, "Equilibrium Wage and Employment Dynamics in a Model of Wage Posting without Commitment," August 2011. NBER WP 17284.

Davis, Steven and Till von Wachter, "Recessions and the Costs of Job Loss," Brookings Papers on Economic Activity, 2012, 43 (2), 1-72.

Diamond, Peter A., "Aggregate Demand Management in Search Equilibrium," Journal of Political Economy, 1982, 90 (5), 881-894.

Fernald, John, "A Quarterly, Utilization-Adjusted Series on Total Factor Productivity," 2012. Federal Reserve Bank of San Francisco Working Paper 2012-19.

Fujita, Shigeru and Giuseppe Moscarini, "Recall and Unemployment," 2013. NBER WP 19640. 
Hagedorn, Marcus and Iourii Manovskii, "The Cyclical Behavior of Equilibrium Unemployment and Vacancies Revisited," The American Economic Review, 2008, 98 (4), pp. 1692-1706.

Hall, Robert, "High Discounts and High Unemployment," 2014. NBER WP 19871.

Hornstein, Andreas, Per Krusell, and Giovanni L. Violante, "Frictional Wage Dispersion in Search Models: A Quantitative Assessment," The American Economic Review, 2011, 101 (7), pp. 2873-2898.

Jolivet, Gregory, Fabien Postel-Vinay, and Jean-Marc Robin, "The empirical content of the job search model: Labor mobility and wage distributions in Europe and the US," European Economic Review, 2006, 50 (4), 877-907.

Kahn, Lisa and Erika McEntarfer, "Employment Cyclicality and Firm Quality," 2014. NBER WP 20698.

Lemieux, Thomas, "Increasing Residual Wage Inequality: Composition Effects, Noisy Data, or Rising Demand for Skill?," The American Economic Review, 2006, 96 (3), 461498.

Ljungqvist, Lars and Thomas J. Sargent, "The Fundamental Surplus in Matching Models," 2015. Mimeo NYU.

Menzio, Guido and Shouyong Shi, "Efficient Search on the Job and the Business Cycle," Journal of Political Economy, 2011, 119 (3), 468-510.

Mortensen, Dale T., Wage Dispersion: Why Are Similar Workers Paid Differently?, MIT Press, 2003.

_ and Christopher A. Pissarides, "Job Creation and Job Destruction in the Theory of Unemployment," The Review of Economic Studies, 1994, 61 (3), 397-415.

Moscarini, Giuseppe and Fabien Postel-Vinay, "The Timing of Labor Market Expansions: New Facts and a New Hypothesis," in Michael Woodford Daron Acemoglu, Kenneth Rogoff, ed., NBER Macroeconomics Annual, Vol. 23 American Economic Association 2009, pp. 1-51.

_ and _ , "The Contribution of Large and Small Employers to Job Creation in Times of High and Low Unemployment," The American Economic Review, 2012, 102 (6), 25092539. 
_ and _, "Stochastic Search Equilibrium," Review of Economic Studies, 2013, 80 (4), $1545-1581$.

_ and _ , "Did the Job Ladder Fail After the Great Recession?," Journal of Labor Economics, Forthcoming.

Petrongolo, Barbara and Christopher A. Pissarides, "Looking into the Black Box: A Survey of the Matching Function," Journal of Economic Literature, 2001, 39 (2), 390-431.

Pissarides, Christopher A., "Short-Run Equilibrium Dynamics of Unemployment, Vacancies, and Real Wages," The American Economic Review, 1985, 75 (4), 676-690.

_ , "The Unemployment Volatility Puzzle: Is Wage Stickiness the Answer?," Econometrica, 2009, 77 (5), 1339-1369.

Postel-Vinay, Fabien and Jean-Marc Robin, "Equilibrium Wage Dispersion with Worker and Employer Heterogeneity," Econometrica, 2002, 70 (6), 2295-2350.

Robin, Jean-Marc, "ON THE DYNAMICS OF UNEMPLOYMENT AND WAGE DISTRIBUTIONS," Econometrica, 2011, 79 (5), 1327-1355.

Shimer, Robert, "The Cyclical Behavior of Equilibrium Unemployment and Vacancies," American Economic Review, 2005, 95 (1), 25-49.

_ , "Reassessing the Ins and Outs of Unemployment," Review of Economic Dynamics, 2012, $15,127-148$.

Spear, Stephen E. and Sanjay Srivastava, "On Repeated Moral Hazard with Discounting," The Review of Economic Studies, 1987, 54 (4), 599-617.

Storesletten, Kjetil, Chris I. Telmer, and Amir Yaron, "Cyclical Dynamics in Idiosyncratic Labor Market Risk," Journal of Political Economy, 2004, 112 (3), 695-717. 


\section{Appendix}

\section{A Proof of Proposition 1}

This proof is adapted from the proof of Proposition 2 presented in Appendix A of Moscarini and Postel-Vina (2013), and follows the same general strategy. For clarity, we amend the notation slightly in this proof by restoring the explicit dependence of various variables on the aggregate state of the economy $(\omega, N)$, rather than subsuming it into a time index as we do in the main text.

We begin with the following preliminary remark. The firms' maximization problem (7) is couched in terms of a joint choice of posted worker values $W$ and hires $h$. This joint choice yields a next-period, state-contingent size:

$$
\mathscr{L}\left(L, W, h, \omega^{\prime}, N\right):=L\left(1-\delta^{\omega^{\prime}}\right)\left(1-s \lambda^{\omega^{\prime}} \bar{F}\left(W \mid \omega^{\prime}, N\right)\right)+h,
$$

so that the hire flow $h=\mathscr{L}-L\left(1-\delta^{\omega^{\prime}}\right)\left(1-s \lambda^{\omega^{\prime}} \bar{F}\left(W \mid \omega^{\prime}, N\right)\right)$. Problem (7) can therefore be recast as an equivalent choice of posted value $W$ and future size $\mathscr{L}$. We shall work with this alternate formulation of the problem in this proof.

We now introduce some more notation. First, we define the retention rate of a firm posting value $W$ in state $\omega$ :

$$
R(W \mid \omega, N):=\left(1-\delta^{\omega^{\prime}}\right)\left(1-s \lambda^{\omega^{\prime}} \bar{F}\left(W \mid \omega^{\prime}, N\right)\right) .
$$

For any choice of $(W, \mathscr{L})$, the firm makes corresponding hires $h=\mathscr{L}-R(W) L$. We further let:

$$
\varphi(p, L, \omega, N):=\omega p L+\beta \int_{\Omega} \delta^{\omega^{\prime}} U\left(\omega^{\prime}, \mathscr{N}\left(\omega^{\prime}, N\right)\right) L Q\left(d \omega^{\prime} \mid \omega\right),
$$

with:

$$
\mathscr{N}\left(\omega^{\prime}, N\right):=\int_{\underline{p}}^{p} \mathscr{L}\left(x, L(x), \omega^{\prime}, N\right) d \Gamma(x) .
$$

and:

$$
\begin{aligned}
& \Phi\left(L, W\left(\omega^{\prime}\right), \mathscr{L}\left(\omega^{\prime}\right), \omega^{\prime}, N\right):=-c\left[\mathscr{L}\left(\omega^{\prime}\right)-L R\left(W\left(\omega^{\prime}\right) \mid \omega^{\prime}\right)\right] \\
&+L \int_{W\left(\omega^{\prime}\right)}^{+\infty} v d R\left(v \mid \omega^{\prime}, N\right)-W\left(\omega^{\prime}\right)\left[\mathscr{L}\left(\omega^{\prime}\right)-L R\left(W\left(\omega^{\prime}\right) \mid \omega^{\prime}\right)\right] .
\end{aligned}
$$

Fix $N$ to be some given c.d.f. over $[\underline{p}, \bar{p}]$. Then, for any function $\mathscr{S}(p, L, \omega)$, we define the following operator $\mathbf{M}^{\mathbf{N}}$ :

$$
\begin{aligned}
\mathbf{M}^{\mathbf{N}} \mathscr{S}(p, L, \omega):=\varphi(p, L, \omega, N)+\beta \int_{\Omega} \max _{W\left(\omega^{\prime}\right), \mathscr{L}\left(\omega^{\prime}\right)}\left\langle\mathscr{S}\left[p, \mathscr{L}\left(\omega^{\prime}\right), \omega^{\prime}\right]\right. \\
\left.+\Phi\left(L, W\left(\omega^{\prime}\right), \mathscr{L}\left(\omega^{\prime}\right), \omega^{\prime}, N\right)\right\rangle Q\left(d \omega^{\prime} \mid \omega\right) .
\end{aligned}
$$


Importantly, as stated in the proposition, we make the following two assumptions: first, the sampling c.d.f. $F(W)$ is everywhere differentiable. This implies differentiability of $R(W)$. Second, the hiring cost function is such that $\varepsilon\left(c^{\prime}\right):=h c^{\prime \prime}(h) / c^{\prime}(h) \geq 1$ for all $h \geq 0$.

We then start the proof with the following lemma:

Lemma 1 Let $\mathscr{S}(p, L, \omega)$ be bounded, continuous in $p$ and $L$, increasing and convex in $L$, and with increasing differences in $(p, L)$ over $(\underline{p}, \bar{p}) \times(0,1)$. Then:

1. $\mathbf{M}^{\mathbf{N}} \mathscr{S}$ is bounded and continuous in $p$ and $L$;

2. There exists a measurable selection $(V(p, L, \omega, N), \mathscr{L}(p, L, \omega, N))$ from the maximizing correspondence associated with $\mathbf{M}^{\mathbf{N}} \mathscr{S}$;

3. Any such measurable selection is such that $V$ and $\mathscr{L}$ are both increasing in $p$ and $L$;

4. $\mathbf{M}^{\mathbf{N}} \mathscr{S}$ is increasing and convex in $L$, and has increasing differences in $(p, L)$ over $(\underline{p}, \bar{p}) \times(0,1)$.

Proof. In this proof, wherever possible without causing confusion, we will make the dependence of all functions on aggregate state variables $\omega$ and $N$ implicit to streamline the notation.

Points 1 and 2 of this proposition follow immediately from the same arguments as in the proof of Lemma 1 in Moscarini and Postel-Vinav (2013), Appendix A. We now turn to the proof of point 3. In each future state $\omega^{\prime}$, the firm solves:

$$
\max _{W, \mathscr{L}}\langle\mathscr{S}(p, \mathscr{L})+\Phi(L, W, \mathscr{L})\rangle
$$

where the dependence on $\omega^{\prime}$ and $N$ of the various functions involved was kept implicit to lighten notation. The FOC for $\mathrm{W}$ is:

$$
0=c^{\prime}[\mathscr{L}-L R(W)] \times L R^{\prime}(W)-[\mathscr{L}-L R(W)]
$$

and that for $\mathscr{L}$ is:

$$
\mathscr{S}_{L, r}(p, \mathscr{L})-W-c^{\prime}[\mathscr{L}-L R(W)] \leq 0 \leq \mathscr{S}_{L, \ell}(p, \mathscr{L})-W-c^{\prime}[\mathscr{L}-L R(W)]
$$

where $\mathscr{S}_{L, r}$ and $\mathscr{S}_{L, \ell}$ denote the right- and left-derivatives of $\mathscr{S}$ w.r.t. $L$, which exist everywhere by convexity of $\mathscr{S}$.

Equation (16) implies that, at an optimal choice of $\mathscr{L}, \mathscr{S}_{L, r}(p, \mathscr{L}) \leq \mathscr{S}_{L, \ell}(p, \mathscr{L})$. But convexity of $\mathscr{S}$ implies that the converse inequality also holds, which proves 
that $\mathscr{S}$ is differentiable w.r.t. $L$ at any optimal choice of $(W, \mathscr{L})$. The FOC for $\mathscr{L}$ thus simply writes as:

$$
0=\mathscr{S}_{L}(p, \mathscr{L})-W-c^{\prime}[\mathscr{L}-L R(W)]
$$

Next, from the properties of $\mathscr{S}$ assumed in the statement of the lemma and from the convexity of $c(\cdot)$, the maximand has increasing differences in $(\mathscr{L}, p)$ and $(\mathscr{L}, L)$, and "flat" differences in $(W, p)$ as it is additively separable in $(W, p)$. Moreover, it has increasing differences in $(\mathscr{L}, W)$ if:

$$
c^{\prime \prime}[\mathscr{L}-L R(W)] \times L R^{\prime}(W)-1 \geq 0
$$

which, substituting the FOC for $W(\underline{15})$, holds around a selection from the optimal correspondence if:

$$
\frac{[\mathscr{L}-L R(W)] c^{\prime \prime}[\mathscr{L}-L R(W)]}{c^{\prime}[\mathscr{L}-L R(W)]} \geq 1,
$$

which is true by the assumption $\varepsilon\left(c^{\prime}\right) \geq 1$.

Let $p_{2}>p_{1}$, and denote corresponding selections from the optimal correspondence by $\left(W_{1}, \mathscr{L}_{1}\right)$ and $\left(W_{2}, \mathscr{L}_{2}\right)$. Then, by revealed preferences:

$$
\begin{aligned}
{\left[\mathscr{S}\left(p_{2}, \mathscr{L}_{2}\right)+\Phi\left(L, W_{2}, \mathscr{L}_{2}\right)\right]-\left[\mathscr{S}\left(p_{2}, \mathscr{L}_{1}\right)+\Phi\left(L, W_{1}, \mathscr{L}_{1}\right)\right] \geq 0 } \\
\geq\left[\mathscr{S}\left(p_{1}, \mathscr{L}_{2}\right)+\Phi\left(L, W_{2}, \mathscr{L}_{2}\right)\right]-\left[\mathscr{S}\left(p_{1}, \mathscr{L}_{1}\right)+\Phi\left(L, W_{1}, \mathscr{L}_{1}\right)\right] \\
\Leftrightarrow \mathscr{S}\left(p_{2}, \mathscr{L}_{2}\right)-\mathscr{S}\left(p_{1}, \mathscr{L}_{2}\right) \geq \mathscr{S}\left(p_{2}, \mathscr{L}_{1}\right)-\mathscr{S}\left(p_{1}, \mathscr{L}_{1}\right)
\end{aligned}
$$

which implies that $\mathscr{L}_{2} \geq \mathscr{L}_{1}$ as $\mathscr{S}$ has increasing differences in $(p, L)$. Similarly, by revealed preferences:

$$
\begin{aligned}
& {\left[\mathscr{S}\left(p_{2}, \mathscr{L}_{2}\right)+\Phi\left(L, W_{2}, \mathscr{L}_{2}\right)\right]-\left[\mathscr{S}\left(p_{2}, \mathscr{L}_{2}\right)+\Phi\left(L, W_{1}, \mathscr{L}_{2}\right)\right] \geq 0} \\
& \geq\left[\mathscr{S}\left(p_{1}, \mathscr{L}_{1}\right)+\Phi\left(L, W_{2}, \mathscr{L}_{1}\right)\right]-\left[\mathscr{S}\left(p_{1}, \mathscr{L}_{1}\right)+\Phi\left(L, W_{1}, \mathscr{L}_{1}\right)\right] \\
& \quad \Leftrightarrow \Phi\left(L, W_{2}, \mathscr{L}_{2}\right)-\Phi\left(L, W_{2}, \mathscr{L}_{1}\right) \geq \Phi\left(L, W_{1}, \mathscr{L}_{2}\right)-\Phi\left(L, W_{1}, \mathscr{L}_{1}\right)
\end{aligned}
$$

which, together with the facts that $\mathscr{L}_{2} \geq \mathscr{L}_{1}$ and that $\Phi$ has increasing differences so long as $\varepsilon\left(c^{\prime}\right) \geq 1$, shows $W_{2}>W_{1}$.

This establishes that any selection $(V(p, L), \mathscr{L}(p, L))$ from the optimal correspondence is such that $V$ and $\mathscr{L}$ are both increasing in $p$. We still need to show that they are also increasing in $L$. To this end, fix $W$ and consider the optimal choice of $\mathscr{L}$ given $W$ and $L$ (call it $\mathscr{L}^{\star}(W, L)$. The corresponding FOC 
writes as:

$$
\begin{aligned}
\mathscr{S}_{L, r}\left(p, \mathscr{L}^{\star}(W, L)\right) & -W-c^{\prime}\left[\mathscr{L}^{\star}(W, L)-L R(W)\right] \\
\leq 0 & \leq \mathscr{S}_{L, \ell}\left(p, \mathscr{L}^{\star}(W, L)\right)-W-c^{\prime}\left[\mathscr{L}^{\star}(W, L)-L R(W)\right] .
\end{aligned}
$$

As before, convexity of $\mathscr{S}$ combined with the FOC above establishes differentiability of $\mathscr{S}$ at $\mathscr{L}^{\star}(W, L)$, implying that the FOC indeed holds with equality:

$$
0=\mathscr{S}_{L}\left(p, \mathscr{L}^{\star}(W, L)\right)-W-c^{\prime}\left[\mathscr{L}^{\star}(W, L)-L R(W)\right]
$$

Next define the maximand:

$$
\mathscr{M}(W, L)=\mathscr{S}\left(p, \mathscr{L}^{\star}(W, L)\right)+\Phi\left(L, W, \mathscr{L}^{\star}(W, L)\right)
$$

This maximand is differentiable w.r.t. $L$ with:

$$
\mathscr{M}_{L}(W, L)=c^{\prime}\left[\mathscr{L}^{\star}(W, L)-L R(W)\right] R(W)+W R(W)+\int_{W}^{+\infty} v d R(v)
$$

Next consider two posted values $W_{2}>W_{1}$. Taking differences of $\mathscr{M}_{L}(W, L)$ :

$$
\begin{aligned}
& \mathscr{M}_{L}\left(W_{2}, L\right)-\mathscr{M}_{L}\left(W_{1}, L\right) \\
&=c^{\prime}\left[\mathscr{L}^{\star}\left(W_{2}, L\right)-L R\left(W_{2}\right)\right] R\left(W_{2}\right)-c^{\prime}\left[\mathscr{L}^{\star}\left(W_{1}, L\right)-L R\left(W_{1}\right)\right] R\left(W_{1}\right) \\
& \quad+W_{2} R\left(W_{2}\right)-W_{1} R\left(W_{1}\right)-\int_{W_{1}}^{W_{2}} v d R(v) \\
&=\left\{c^{\prime}\left[\mathscr{L}^{\star}\left(W_{2}, L\right)-L R\left(W_{2}\right)\right]-c^{\prime}\left[\mathscr{L}^{\star}\left(W_{1}, L\right)-L R\left(W_{1}\right)\right]\right\} R\left(W_{1}\right) \\
& \quad+c^{\prime}\left[\mathscr{L}^{\star}\left(W_{2}, L\right)-L R\left(W_{2}\right)\right] \times\left[R\left(W_{2}\right)-R\left(W_{1}\right)\right]+\int_{W_{1}}^{W_{2}} R(v) d v
\end{aligned}
$$

where the second equality uses integration by parts. Substituting the FOC (17):

$$
\begin{aligned}
& \mathscr{M}_{L}\left(W_{2}, L\right)-\mathscr{M}_{L}\left(W_{1}, L\right)=\left\{\mathscr{S}_{L}\left[p, \mathscr{L}^{\star}\left(W_{2}, L\right)\right]-\mathscr{S}_{L}\left[p, \mathscr{L}^{\star}\left(W_{1}, L\right)\right]\right\} R\left(W_{1}\right) \\
& +c^{\prime}\left[\mathscr{L}^{\star}\left(W_{2}, L\right)-L R\left(W_{2}\right)\right] \times\left[R\left(W_{2}\right)-R\left(W_{1}\right)\right]+\int_{W_{1}}^{W_{2}}\left[R(v)-R\left(W_{1}\right)\right] d v .
\end{aligned}
$$

All terms in the r.h.s. of the above equation are positive: the first one by convexity of $\mathscr{S}$ w.r.t. $L$, and the other two from the fact that $R(\cdot)$ is an increasing function. Now, a solution $(V(p, L), \mathscr{L}(p, L))$ to the initial problem (14) also solves $V=\operatorname{argmax}_{W} \mathscr{M}(L, W)$ and $\mathscr{L}=\mathscr{L}^{\star}(V, L)$. Because the maximand in the latter problem has increasing differences in $(W, L)$, it must be the case that $V(p, L)$ is increasing in $L$. And because $\partial \mathscr{L}^{\star} / \partial L$ and $\partial \mathscr{L}^{\star} / \partial W$ are both positive 
(provided that $\varepsilon\left(c^{\prime}\right) \geq 1$ ), it must be the case that $\mathscr{L}(p, L)=\mathscr{L}^{\star}(V(p, L), L)$ is also increasing in $L$.

Now on to point 4 . Inspection of (13), in combination with the fact that $\mathscr{S}$ is differentiable w.r.t. $L$ at any optimal solution, shows that $\mathbf{M}^{\mathbf{N}} \mathscr{S}$ is in fact differentiable w.r.t. $L$ (a stronger property than claimed in the lemma). Furthermore:

$$
\begin{array}{rl}
\frac{\partial}{\partial L} \mathbf{M}^{\mathbf{N}} & \mathscr{S}(p, L, \omega)=\omega p+\beta \int_{\Omega} \delta^{\omega^{\prime}} U\left(\omega^{\prime}\right) Q\left(d \omega^{\prime} \mid \omega\right) \\
& +\beta \int_{\Omega}\left\{c^{\prime}\left[\mathscr{L}\left(p, L, \omega^{\prime}\right)-L R\left(V\left(p, L, \omega^{\prime}\right) \mid \omega^{\prime}\right)\right] R\left(V\left(p, L, \omega^{\prime}\right) \mid \omega^{\prime}\right)\right. \\
& \left.+\int_{V\left(p, L, \omega^{\prime}\right)}^{+\infty} v d R\left(v \mid \omega^{\prime}\right)+V\left(p, L, \omega^{\prime}\right) R\left(V\left(p, L, \omega^{\prime}\right) \mid \omega^{\prime}\right)\right\} Q\left(d \omega^{\prime} \mid \omega\right)
\end{array}
$$

This latter equation readily shows that $\mathbf{M}^{\mathbf{N}} \mathscr{S}$ is increasing in $L$.

What is left is for us to establish that $\mathbf{M}^{\mathbf{N}} \mathscr{S}$ is convex w.r.t. $L$ and has increasing differences in $(L, p)$. To this end, first note that substitution of the FOC (16) into (18) yields an alternative expression for $\partial \mathbf{M}^{\mathbf{N}} \mathscr{S} / \partial L$ :

$$
\begin{aligned}
& \frac{\partial}{\partial L} \mathbf{M}^{\mathbf{N}} \mathscr{S}(p, L, \omega)=\omega p+\beta \int_{\Omega} \delta^{\omega^{\prime}} U\left(\omega^{\prime}\right) Q\left(d \omega^{\prime} \mid \omega\right) \\
+ & \beta \int_{\Omega}\left\{\mathscr{S}_{L}\left(p, \mathscr{L}\left(p, L, \omega^{\prime}\right)\right) \times R\left(V\left(p, L, \omega^{\prime}\right) \mid \omega^{\prime}\right)+\int_{V\left(p, L, \omega^{\prime}\right)}^{+\infty} v d R\left(v \mid \omega^{\prime}\right)\right\} Q\left(d \omega^{\prime} \mid \omega\right)
\end{aligned}
$$

Now take $L_{2}>L_{1}$ :

$$
\begin{gathered}
\frac{\partial}{\partial L} \mathbf{M}^{\mathbf{N}} \mathscr{S}\left(p, L_{2}, \omega\right)-\frac{\partial}{\partial L} \mathbf{M}^{\mathbf{N}} \mathscr{S}\left(p, L_{1}, \omega\right) \\
=\beta \int_{\Omega}\left\{\mathscr{S}_{L}\left(p, \mathscr{L}\left(p, L_{2}, \omega^{\prime}\right)\right) \times R\left(V\left(p, L_{2}, \omega^{\prime}\right) \mid \omega^{\prime}\right)\right. \\
\left.-\mathscr{S}_{L}\left(p, \mathscr{L}\left(p, L_{1}, \omega^{\prime}\right)\right) \times R\left(V\left(p, L_{1}, \omega^{\prime}\right) \mid \omega^{\prime}\right)-\int_{V\left(p, L_{1}, \omega^{\prime}\right)}^{V\left(p, L_{2}, \omega^{\prime}\right)} v d R\left(v \mid \omega^{\prime}\right)\right\} Q\left(d \omega^{\prime} \mid \omega\right) \\
=\beta \int_{\Omega}\left\{\left[\mathscr{S}_{L}\left(p, \mathscr{L}\left(p, L_{2}, \omega^{\prime}\right)\right)-\mathscr{S}_{L}\left(p, \mathscr{L}\left(p, L_{1}, \omega^{\prime}\right)\right)\right] \times R\left(V\left(p, L_{1}, \omega^{\prime}\right) \mid \omega^{\prime}\right)\right. \\
\left.\quad+\int_{V\left(p, L_{1}, \omega^{\prime}\right)}^{V\left(p, L_{2}, \omega^{\prime}\right)}\left[\mathscr{S}_{L}\left(p, \mathscr{L}\left(p, L_{2}, \omega^{\prime}\right)\right)-v\right] d R\left(v \mid \omega^{\prime}\right)\right\} Q\left(d \omega^{\prime} \mid \omega\right)
\end{gathered}
$$

which is positive, by convexity of $\mathscr{S}$, the fact that both $V$ and $\mathscr{L}$ are increasing in $L$, and the fact that $\mathscr{S}_{L}\left(p, \mathscr{L}\left(p, L_{2}, \omega^{\prime}\right)\right) \geq V\left(p, L_{2}, \omega^{\prime}\right)$. This establishes 
convexity of $\mathbf{M}^{\mathbf{N}} \mathscr{S}$ w.r.t. $L$. Increasing differences in $(L, p)$ is follows from similar steps (only taking differences in $p$ of $\partial \mathbf{M}^{\mathbf{N}} \mathscr{S} / \partial L$ ), so we omit the details.

Now consider the set of functions defined over $[\underline{p}, \bar{p}] \times[0,1] \times \Omega$ that are continuous in $(p, L)$ and call it $\mathscr{C}_{[\underline{p}, \bar{p}] \times[0,1] \times \Omega}$. That set is a Banach space when endowed with the sup norm. As Lemma 1 suggests we will be interested in the properties of a subset $\mathscr{C}_{[\underline{p}, \bar{p}] \times[0,1] \times \Omega} \subset$ $\mathscr{C}_{[\underline{p}, \bar{p}] \times[0,1] \times \Omega}$ of functions that are increasing and convex in $L$ and have increasing differences in $(p, L)$. We next state two ancillary lemmas, which will establish as a corollary (Corollary 1) that $\mathscr{C}_{[\underline{p}, \bar{p}] \times[0,1] \times \Omega}^{\prime}$ is closed in $\mathscr{C}_{[\underline{p}, \bar{p}] \times[0,1] \times \Omega}$ under the sup norm.

Lemma 2 Let $X$ be an interval in $\mathbb{R}$ and $f_{n}: X \rightarrow \mathbb{R}, N \in \mathbb{N}$ such that $\left\{f_{n}\right\}$ converges uniformly to $f$. Then:

1. if $f_{n}$ is nondecreasing for all $n$, so is $f$;

2. if $f_{n}$ is convex for all $n$, so is $f$.

Proof. See the appendix of Moscarini and Postel-Vinay (2013).

Lemma 3 Let $X \subset \mathbb{R}^{2}$ be a convex set and $f_{n}: X \rightarrow \mathbb{R}, N \in \mathbb{N}$ be functions with increasing differences such that $\left\{f_{n}\right\}$ converges uniformly to $f$. Then $f$ has increasing differences.

Proof. See the appendix of Moscarini and Postel-Vinay (2013).

Corollary 1 The set $\mathscr{C}_{[\underline{p}, \bar{p}] \times[0,1] \times \Omega}^{\prime}$ of functions defined over $[\underline{p}, \bar{p}] \times[0,1] \times \Omega$ that are increasing and convex in $L$ and have increasing differences in $(p, L)$ is a closed subset of $\mathscr{C}_{[\underline{p}, \bar{p}] \times[0,1] \times \Omega}$ under the sup norm.

The latter corollary establishes that, given a fixed $N$, the functions that are relevant to Lemma 1 live in a closed subset of a Banach space of functions under the sup norm. The following lemma shows that the operator considered in Lemma 1 is a contraction under that same norm.

Lemma 4 The operator $\mathbf{M}^{N}$ defined in (13) maps $\mathscr{C}_{[\underline{p}, \bar{p}] \times[0,1] \times \Omega}^{\prime}$ into itself and is a contraction of modulus $\beta$ under the sup norm.

Proof. That $\mathbf{M}^{N}$ maps $\mathscr{C}_{[\underline{p}, \bar{p}] \times[0,1] \times \Omega}^{\prime}$ into itself flows directly from part of the proof of Lemma 1, To prove that $\mathbf{M}^{N}$ is a contraction, we can easily check using (13) that $\mathbf{M}^{\mathbf{N}}$ satisfies Blackwell's sufficient conditions with modulus $\beta$. 
We are now in a position to prove the proposition. Given the initially fixed $N$, the operator $\mathbf{M}^{\mathbf{N}}$, which by Lemma 4 is a contraction from $\mathscr{C}_{[\underline{p}, \bar{p}] \times[0,1] \times \Omega}$ into itself, and has a unique fixed point $\mathscr{S}_{N}$ in that set (by the Contraction Mapping Theorem). Moreover, since $\mathscr{C}_{[\underline{p}, \bar{p}] \times[0,1] \times \Omega}^{\prime}$ is a closed subset of $\mathscr{C}_{[\underline{p}, \bar{p}] \times[0,1] \times \Omega}$ (Lemma 21) and since $\mathbf{M}^{\mathbf{N}}$ also maps $\mathscr{C}_{[\underline{p}, \bar{p}] \times[0,1] \times \Omega}^{\prime}$ into itself (Lemma 1), that fixed point $\mathscr{S}_{N}$ belongs to $\mathscr{C}_{[\underline{p}, \bar{p}] \times[0,1] \times \Omega}^{\prime}$.

Summing up, what we have established thus far is that for any fixed $N \in \mathscr{C}_{[\underline{p}, \bar{p}]}$, the operator $\mathbf{M}^{\mathbf{N}}$ over functions of $(p, L, \omega)$ has a unique, bounded and continuous fixed point $\mathscr{S}_{N}^{\star}=\mathbf{M}^{\mathbf{N}} \mathscr{S}_{N}^{\star} \in \mathscr{C}_{[\underline{p}, \bar{p}] \times[0,1] \times \Omega}^{\prime} \subset \mathscr{C}_{[\underline{p}, \bar{p}] \times[0,1] \times \Omega}$.

We finally turn to the Bellman operator $\mathbf{M}$ which is relevant to the firm's problem. That operator $\mathbf{M}$ applies to functions $\overline{\mathscr{S}}$ defined on $[\underline{p}, \bar{p}] \times[0,1] \times \Omega \times \mathscr{C}_{[\underline{p}, \bar{p}]}$ and is defined as the following "extension" of $\mathbf{M}^{\mathbf{N}}$ :

$$
\begin{aligned}
\mathbf{M} \overline{\mathscr{S}}(p, L, \omega, N):=\varphi(p, L, \omega, N)+\beta \int_{\Omega} \max _{W\left(\omega^{\prime}\right), \mathscr{L}\left(\omega^{\prime}\right)}\left\langle\overline{\mathscr{S}}\left[p, \mathscr{L}\left(\omega^{\prime}\right), \omega^{\prime}\right]\right. \\
\left.+\Phi\left(L, W\left(\omega^{\prime}\right), \mathscr{L}\left(\omega^{\prime}\right), \omega^{\prime}, N\right)\right\rangle Q\left(d \omega^{\prime} \mid \omega\right) .
\end{aligned}
$$

If an equilibrium exists, then a firm has a best response and a value $S$ which solves $S=\operatorname{M} S$. For every $N \in \mathscr{C}_{[\underline{p}, \bar{p}]}$, by definition of $\mathbf{M}$ and $\mathbf{M}^{\mathbf{N}}$ this implies $S=\mathbf{M}^{\mathbf{N}} S$. Since the fixed point of $\mathbf{M}^{\mathbf{N}}$ is unique, if $S=\mathbf{M} S$ exists then for every fixed $N \in \mathscr{C}_{[\underline{p}, \bar{p}]}$ we have for all $(p, L, \omega) \in[\underline{p}, \bar{p}] \times[0,1] \times \Omega: S(p, L, \omega, N)=\mathscr{S}_{N}^{\star}(p, L, \omega)$. Therefore, if the value function $S$ and an equilibrium of the contract-posting game exist, then $S \in \mathscr{C}_{[\underline{p}, \bar{p}] \times[0,1] \times \Omega}^{\prime}$ : the typical firm's value function is continuous in $p$ and $L$, increasing and convex in $L$ and has increasing differences in $(p, L)$. By the same standard comparative statics arguments that we invoked in the proof of Lemma 1, the maximizing correspondence is increasing in $p$ and $L$ in the strong set sense, hence all of its measurable selections are weakly increasing in $p$ and $L$.

\section{B The computation algorithm}

We describe the algorithm that we use to approximate numerically RPE contracts. We start with the case of exogenous vacancies and hiring for notational simplicity, and return to the general case of endogenous hiring at the end.

\section{B.1 RPE Dynamics}

With exogenous and uniform sampling weights, in any RPE, aggregate ads and sampling distribution are $A_{t}(\omega)=1, F_{t}(p)=\Gamma(p)$, the job finding and vacancy filling rates are:

$$
\lambda\left(\omega_{t}, N_{t-1}\right)=m\left(1, \frac{1}{1-N_{t-1}(\bar{p})+s\left(1-\delta\left(\omega_{t}\right)\right) N_{t-1}(\bar{p})}\right)
$$




$$
\eta\left(\omega_{t}, N_{t-1}\right)=m\left(1-N_{t-1}(\bar{p})+s\left(1-\delta\left(\omega_{t}\right)\right) N_{t-1}(\bar{p}), 1\right)
$$

The law of motion of firm-level employment is:

$$
\begin{aligned}
& \mathcal{L}\left(p \mid \omega_{t}, N_{t-1}\right) \\
& =N_{t-1}(p)\left(1-\delta\left(\omega_{t}\right)\right)\left[1-s \lambda\left(\omega_{t}, N_{t-1}\right) \bar{\Gamma}(p)\right]+\eta\left(\omega_{t}, N_{t-1}\right) \frac{1-N_{t-1}(\bar{p})+s\left(1-\delta\left(\omega_{t}\right)\right) N_{t-1}(p)}{1-N_{t-1}(\bar{p})+s\left(1-\delta\left(\omega_{t}\right)\right) N_{t-1}(\bar{p})} \\
& =N_{t-1}(p)\left(1-\delta\left(\omega_{t}\right)\right)\left[1-s \lambda\left(\omega_{t}, N_{t-1}\right) \bar{\Gamma}(p)\right]+\lambda\left(\omega_{t}, N_{t-1}\right)\left[1-N_{t-1}(\bar{p})+s\left(1-\delta\left(\omega_{t}\right)\right) N_{t-1}(p)\right]
\end{aligned}
$$

Consequently, the employment distribution evolves according to

$$
\begin{aligned}
& \mathcal{N}\left(p \mid \omega_{t}, N_{t-1}\right)=\int_{\underline{p}}^{p} \mathcal{L}\left(x \mid \omega_{t}, N_{t-1}\right) d \Gamma(x) \\
& =\left(1-\delta\left(\omega_{t}\right)\right) \int_{\underline{p}}^{p}\left\{N_{t-1}(x)\left[1+s \lambda\left(\omega_{t}, N_{t-1}\right) \Gamma(x)\right]\right\} d \Gamma(x)+\lambda\left(\omega_{t}, N_{t-1}\right)\left[1-N_{t-1}(\bar{p})\right] \Gamma(p)
\end{aligned}
$$

We look for contracts that support this RPE allocation. That is, if all firms follow RPE strategies, so that the above dynamics apply, we look for the value that each firm $p$ offers as a best-response.

\section{B.2 Euler equation}

Let $V\left(p \mid \omega_{t}, N_{t-1}\right)$ be the optimal policy given aggregate states $\omega_{t}, N_{t-1}, U\left(\omega_{t}, N_{t-1}\right)$ the value of unemployment, $\mu\left(p \mid \omega_{t}, N_{t-1}\right)$ the shadow marginal value of one more worker. Then using the Bellman equation of the unemployed worker

$$
\begin{aligned}
U\left(\omega_{t}, N_{t-1}\right)= & b\left(\omega_{t}\right)+\beta \mathbf{E}_{\omega_{t+1} \mid \omega_{t}}\left\{U\left(\omega_{t+1}, \mathcal{N}\left(\cdot \mid \omega_{t}, N_{t-1}\right)\right)+\lambda\left(\omega_{t+1}, \mathcal{N}\left(\cdot \mid \omega_{t}, N_{t-1}\right)\right)\right. \\
& \left.\times \int_{\underline{p}}^{\bar{p}} \max \left\langle V\left(x \mid \omega_{t+1}, \mathcal{N}\left(\cdot \mid \omega_{t}, N_{t-1}\right)\right)-U\left(\omega_{t+1}, \mathcal{N}\left(\cdot \mid \omega_{t}, N_{t-1}\right)\right), 0\right\rangle d \Gamma(x)\right\}
\end{aligned}
$$

the FOC for an optimal offered value can be written as

$$
V\left(p \mid \omega_{t}, N_{t-1}\right)-U\left(\omega_{t}, N_{t-1}\right)=\int_{\underline{p}}^{p} \frac{\left[\mu\left(x \mid \omega_{t}, N_{t-1}\right)-U\left(\omega_{t}, N_{t-1}\right)\right] s\left(1-\delta\left(\omega_{t}\right)\right) d N_{t-1}(x)}{1-N_{t-1}(\bar{p})+s\left(1-\delta\left(\omega_{t}\right)\right) N_{t-1}(\bar{p})}
$$


and the Euler equation as

$$
\begin{gathered}
\mu\left(p \mid \omega_{t}, N_{t-1}\right)-U\left(\omega_{t}, N_{t-1}\right)=\omega_{t} p-b\left(\omega_{t}\right) \\
+\beta \mathbf{E}_{\omega_{t+1} \mid \omega_{t}}\left\{\left(1-\delta\left(\omega_{t+1}\right)\right)\left[1-s \lambda\left(\omega_{t+1}, \mathcal{N}\left(\cdot \mid \omega_{t}, N_{t-1}\right)\right) \bar{\Gamma}(p)\right]\right. \\
\quad \times\left[\mu\left(p \mid \omega_{t+1}, \mathcal{N}\left(\cdot \mid \omega_{t}, N_{t-1}\right)\right)-U\left(\omega_{t+1}, \mathcal{N}\left(\cdot \mid \omega_{t}, N_{t-1}\right)\right)\right] \\
+\left(1-\delta\left(\omega_{t+1}\right)\right) s \lambda\left(\omega_{t+1}, \mathcal{N}\left(\cdot \mid \omega_{t}, N_{t-1}\right) \int_{p}^{\bar{p}}\left[V\left(x \mid \omega_{t+1}, \mathcal{N}\left(\cdot \mid \omega_{t}, N_{t-1}\right)\right)-U\left(\omega_{t+1}, \mathcal{N}\left(\cdot \mid \omega_{t}, N_{t-1}\right)\right)\right] d \Gamma(x)\right. \\
-\lambda\left(\omega_{t+1}, \mathcal{N}\left(\cdot \mid \omega_{t}, N_{t-1}\right) \int_{\underline{p}}^{\bar{p}}\left[V\left(x \mid \omega_{t+1}, \mathcal{N}\left(\cdot \mid \omega_{t}, N_{t-1}\right)\right)-U\left(\omega_{t+1}, \mathcal{N}\left(\cdot \mid \omega_{t}, N_{t-1}\right)\right)\right] d \Gamma(x)\right\}
\end{gathered}
$$

Let

$$
\sigma\left(p \mid \omega_{t}, N_{t-1}\right):=\mu\left(p \mid \omega_{t}, N_{t-1}\right)-U\left(\omega_{t}, N_{t-1}\right)
$$

so that

$$
\begin{aligned}
& V\left(p \mid \omega_{t+1}, \mathcal{N}\left(\cdot \mid \omega_{t}, N_{t-1}\right)\right)-U\left(\omega_{t+1}, \mathcal{N}\left(\cdot \mid \omega_{t}, N_{t-1}\right)\right) \\
& \quad=s\left(1-\delta\left(\omega_{t+1}\right)\right) \int_{\underline{p}}^{p} \frac{\sigma\left(x \mid \omega_{t+1}, \mathcal{N}\left(\cdot \mid \omega_{t}, N_{t-1}\right)\right)}{1-\mathcal{N}\left(\bar{p} \mid \omega_{t}, N_{t-1}\right)+s\left(1-\delta\left(\omega_{t+1}\right)\right) \mathcal{N}\left(\bar{p} \mid \omega_{t}, N_{t-1}\right)} d \mathcal{N}\left(x \mid \omega_{t}, N_{t-1}\right)
\end{aligned}
$$

Substituting in, $\sigma\left(p \mid \omega_{t}, N_{t-1}\right)$ solves the Euler equation

$$
\begin{gathered}
\sigma\left(p \mid \omega_{t}, N_{t-1}\right)=\omega_{t} p-b\left(\omega_{t}\right) \\
+\beta \mathbf{E}_{\omega_{t+1} \mid \omega_{t}}\left\{\left(1-\delta\left(\omega_{t+1}\right)\right)\left[1-s \lambda\left(\omega_{t+1}, \mathcal{N}\left(\cdot \mid \omega_{t}, N_{t-1}\right)\right) \bar{\Gamma}(p)\right] \sigma\left(p \mid \omega_{t+1}, \mathcal{N}\left(\cdot \mid \omega_{t}, N_{t-1}\right)\right)\right. \\
+\left(1-\delta\left(\omega_{t+1}\right)\right)^{2} s^{2} \lambda\left(\omega_{t+1}, \mathcal{N}\left(\cdot \mid \omega_{t}, N_{t-1}\right)\right) \int_{p}^{\bar{p}} \int_{\underline{p}}^{x} \frac{\sigma\left(y \mid \omega_{t+1}, \mathcal{N}\left(\cdot \mid \omega_{t}, N_{t-1}\right)\right) d \mathcal{N}\left(y \mid \omega_{t}, N_{t-1}\right) d \Gamma(x)}{1-\mathcal{N}\left(\bar{p} \mid \omega_{t}, N_{t-1}\right)+s\left(1-\delta\left(\omega_{t+1}\right)\right) \mathcal{N}\left(\bar{p} \mid \omega_{t}, N_{t-1}\right)} \\
\left.-\left(1-\delta\left(\omega_{t+1}\right)\right) s \lambda\left(\omega_{t+1}, \mathcal{N}\left(\cdot \mid \omega_{t}, N_{t-1}\right)\right) \int_{\underline{p}}^{\bar{p}} \int_{\underline{p}}^{x} \frac{\sigma\left(y \mid \omega_{t+1}, \mathcal{N}\left(\cdot \mid \omega_{t}, N_{t-1}\right)\right) d \mathcal{N}\left(y \mid \omega_{t}, N_{t-1}\right) d \Gamma(x)}{1-\mathcal{N}\left(\bar{p} \mid \omega_{t}, N_{t-1}\right)+s\left(1-\delta\left(\omega_{t+1}\right)\right) \mathcal{N}\left(\bar{p} \mid \omega_{t}, N_{t-1}\right)}\right\}
\end{gathered}
$$

where $\lambda\left(p \mid \omega_{t}, N_{t-1}\right)$ and $\mathcal{N}\left(p \mid \omega_{t}, N_{t-1}\right)$ were defined before in (19) and (20).

\section{B.3 Computation}

Fix a large $T>0$, draw a history of aggregate shocks $\omega^{\star}=\left\{\omega_{t}^{\star}\right\}_{t=1}^{T}$ and compute the associated $N^{\star}=\left\{N_{t}^{\star}\right\}_{t=1}^{T}$ from $N_{t}^{\star}=\mathcal{N}\left(p \mid \omega_{t}, N_{t-1}^{\star}\right)$. We want to compute, at least approximately, the realized path of

$$
\sigma\left(p \mid \omega_{t}^{\star}, N_{t-1}^{\star}\right):=\sigma_{t}^{\star}(p)
$$


where the dependence on $N_{t-1}^{\star}$ is encoded in the subscript $t$ of $\sigma_{t}^{\star}$. From this sequence of functions of $p$ we can compute offered values (and adverts in the endogenous vacancy case addressed below). In order to compute these values, we can apply the Euler equation (21) to $\left(\omega_{t}^{\star}, N_{t-1}^{\star}\right)$ :

$$
\begin{aligned}
\sigma\left(p \mid \omega_{t}^{\star}, N_{t-1}^{\star}\right) & =\omega_{t}^{\star} p-b\left(\omega_{t}^{\star}\right) \\
+ & \beta \mathbf{E}_{\omega_{t+1} \mid \omega_{t}^{\star}}\left\{\left(1-\delta\left(\omega_{t+1}\right)\right)\left[1-s \lambda\left(\omega_{t+1}, N_{t}^{\star}\right) \bar{\Gamma}(p)\right] \sigma\left(p \mid \omega_{t+1}, N_{t}^{\star}\right)\right. \\
+ & \left(1-\delta\left(\omega_{t+1}\right)\right)^{2} s^{2} \lambda\left(\omega_{t+1}, N_{t}^{\star}\right) \int_{p}^{\bar{p}} \int_{\underline{p}}^{x} \frac{\sigma\left(y \mid \omega_{t+1}, N_{t}^{\star}\right) d N_{t}^{\star}(y) d \Gamma(x)}{1-N_{t}^{\star}(\bar{p})+s\left(1-\delta\left(\omega_{t+1}\right)\right) N_{t}^{\star}(\bar{p})} \\
& \left.-\left(1-\delta\left(\omega_{t+1}\right)\right) s \lambda\left(\omega_{t+1}, N_{t}^{\star}\right) \int_{\underline{p}}^{\bar{p}} \int_{\underline{p}}^{x} \frac{\sigma\left(y \mid \omega_{t+1}, N_{t}^{\star}\right) d N_{t}^{\star}(y) d \Gamma(x)}{1-N_{t}^{\star}(\bar{p})+s\left(1-\delta\left(\omega_{t+1}\right)\right) N_{t}^{\star}(\bar{p})}\right\}
\end{aligned}
$$

To compute the r.h.s. we need to compute $\sigma\left(y \mid \omega_{t+1}, N_{t}^{\star}\right)$ for every $y$ and every $\omega_{t+1}$. To do so, we apply again (21) to $N_{t-1}^{\star}$ and any possible value of $\omega_{t}$

$$
\begin{aligned}
& \sigma\left(p \mid \omega_{t}, N_{t-1}^{\star}\right)=\omega_{t} p-b\left(\omega_{t}\right) \\
+ & \beta \mathbf{E}_{\omega_{t+1} \mid \omega_{t}}\left\{\left(1-\delta\left(\omega_{t+1}\right)\right)\left[1-s \lambda\left(\omega_{t+1}, \mathcal{N}\left(\cdot \mid \omega_{t}, N_{t-1}^{\star}\right)\right) \bar{\Gamma}(p)\right] \sigma\left(p \mid \omega_{t+1}, \mathcal{N}\left(\cdot \mid \omega_{t}, N_{t-1}^{\star}\right)\right)\right. \\
+ & \left(1-\delta\left(\omega_{t+1}\right)\right)^{2} s^{2} \lambda\left(\omega_{t+1}, \mathcal{N}\left(\cdot \mid \omega_{t}, N_{t-1}^{\star}\right)\right) \int_{p}^{\bar{p}} \int_{\underline{p}}^{x} \frac{\sigma\left(y \mid \omega_{t+1}, \mathcal{N}\left(\cdot \mid \omega_{t}, N_{t-1}^{\star}\right)\right) d \mathcal{N}\left(y \mid \omega_{t}, N_{t-1}^{\star}\right) d \Gamma(x)}{1-\mathcal{N}\left(\bar{p} \mid \omega_{t}, N_{t-1}^{\star}\right)+s\left(1-\delta\left(\omega_{t+1}\right)\right) \mathcal{N}\left(\bar{p} \mid \omega_{t}, N_{t-1}^{\star}\right)} \\
- & \left.\left(1-\delta\left(\omega_{t+1}\right)\right) s \lambda\left(\omega_{t+1}, \mathcal{N}\left(\cdot \mid \omega_{t}, N_{t-1}^{\star}\right)\right) \int_{\underline{p}}^{\bar{p}} \int_{\underline{p}}^{x} \frac{\sigma\left(y \mid \omega_{t+1}, \mathcal{N}\left(\cdot \mid \omega_{t}, N_{t-1}^{\star}\right)\right) d \mathcal{N}\left(y \mid \omega_{t}, N_{t-1}^{\star}\right) d \Gamma(x)}{1-\mathcal{N}\left(\bar{p} \mid \omega_{t}, N_{t-1}^{\star}\right)+s\left(1-\delta\left(\omega_{t+1}\right)\right) \mathcal{N}\left(\bar{p} \mid \omega_{t}, N_{t-1}^{\star}\right)}\right\}
\end{aligned}
$$

To compute the r.h.s. we need to compute $\mathcal{N}\left(\cdot \mid \omega_{t}, N_{t-1}^{\star}\right)$ for each $\omega_{t}$, which is feasible, and $\sigma\left(y \mid \omega_{t+1}, \mathcal{N}\left(\cdot \mid \omega_{t}, N_{t-1}^{\star}\right)\right)$ for every value of $\mathcal{N}\left(\cdot \mid \omega_{t}, N_{t-1}^{\star}\right)$. For that, it is sufficient (but not necessary) to know the entire map $\sigma\left(y \mid \omega_{t+1}, N_{t}\right)$ for every $\left(\omega_{t+1}, N_{t}\right)$, which is infeasible, because $N_{t}$ is infinite-dimensional.

\section{B.4 An "anticipatory" approximation}

In $\sigma\left(y \mid \omega_{t+1}, N_{t}\right)$, we approximate every $N_{t}$ which could have been generated by $\mathcal{N}\left(\cdot \mid \omega_{t}, N_{t-1}^{\star}\right)$ depending on the realization of $\omega_{t}$ with the $N_{t}^{\star}=\mathcal{N}\left(\cdot \mid \omega_{t}^{\star}, N_{t-1}^{\star}\right)$ realized on this RPE path. In so doing, we effectively reset the dimensionality of each firm's state space to the cardinality of $\Omega$ (the support of $\omega$ ) in every period. Starting from a terminal condition $\widetilde{\sigma}\left(p \mid \omega_{T+1}, N_{T}^{\star}\right)=\omega_{T+1} p-b\left(\omega_{T+1}\right)$, we compute recursively the approximation $\widetilde{\sigma}\left(y \mid \omega_{t+1}, N_{t}^{\star}\right)$ 
back in time $t=T, T-1, \cdots, 0$ using:

$$
\begin{aligned}
& \quad \tilde{\sigma}\left(p \mid \omega_{t}, N_{t-1}^{\star}\right)=\omega_{t} p-b\left(\omega_{t}\right) \\
& +\beta \mathbf{E}_{\omega_{t+1} \mid \omega_{t}}\left\{\left(1-\delta\left(\omega_{t+1}\right)\right)\left[1-s \lambda\left(\omega_{t+1}, \mathcal{N}\left(\cdot \mid \omega_{t}, N_{t-1}^{\star}\right)\right) \bar{\Gamma}(p)\right] \tilde{\sigma}\left(p \mid \omega_{t+1}, \mathcal{N}\left(\cdot \mid \omega_{t}, N_{t-1}^{\star}\right)\right)\right. \\
& +\left(1-\delta\left(\omega_{t+1}\right)\right)^{2} s^{2} \lambda\left(\omega_{t+1}, \mathcal{N}\left(\cdot \mid \omega_{t}, N_{t-1}^{\star}\right)\right) \int_{p}^{\bar{p}} \int_{\underline{p}}^{x} \frac{\tilde{\sigma}\left(y \mid \omega_{t+1}, N_{t}^{\star}\right) d \mathcal{N}\left(y \mid \omega_{t}, N_{t-1}^{\star}\right) d \Gamma(x)}{1-\mathcal{N}\left(\bar{p} \mid \omega_{t}, N_{t-1}^{\star}\right)+s\left(1-\delta\left(\omega_{t+1}\right)\right) \mathcal{N}\left(\bar{p} \mid \omega_{t}, N_{t-1}^{\star}\right)} \\
& \left.-\left(1-\delta\left(\omega_{t+1}\right)\right) s \lambda\left(\omega_{t+1}, \mathcal{N}\left(\cdot \mid \omega_{t}, N_{t-1}^{\star}\right)\right) \int_{\underline{p}}^{\bar{p}} \int_{\underline{p}}^{x} \frac{\tilde{\sigma}\left(y \mid \omega_{t+1}, N_{t}^{\star}\right) d \mathcal{N}\left(y \mid \omega_{t}, N_{t-1}^{\star}\right) d \Gamma(x)}{1-\mathcal{N}\left(\bar{p} \mid \omega_{t}, N_{t-1}^{\star}\right)+s\left(1-\delta\left(\omega_{t+1}\right)\right) \mathcal{N}\left(\bar{p} \mid \omega_{t}, N_{t-1}^{\star}\right)}\right\}
\end{aligned}
$$

We then truncate the last part of the history as a 'burn-in' period, and approximate the desired $\sigma\left(p \mid \omega_{t}^{\star}, N_{t-1}^{\star}\right):=\sigma_{t}^{\star}(p)$ with $\widetilde{\sigma}\left(p \mid \omega_{t}^{\star}, N_{t-1}^{\star}\right)$, the function just obtained evaluated on the realized path.

Conceptually, in this approximation, a firm still views aggregate productivity $\omega_{t}$ as random at the beginning of period $t$ and takes conditional expectations w.r.t. this random variable, but evaluates the future marginal value of a new employee as if the period- $t$ realized employment distribution $\left(\mathcal{N}\left(\cdot \mid \omega_{t}, N_{t-1}^{\star}\right)\right)$ were always the one occurring on the equilibrium path $\left(N_{t}^{\star}=\mathcal{N}\left(\cdot \mid \omega_{t}^{\star}, N_{t-1}^{\star}\right)\right)$, regardless of $\omega_{t}$. Since $N_{t}$ is a slow-moving object, the deviation

$$
\sup _{p, \omega}\left|N_{t}^{\star}(p)-\mathcal{N}\left(p \mid \omega, N_{t-1}^{\star}\right)\right|
$$

is likely to be small one period ahead, and the quality of the approximation rests on the continuity of the functional $\sigma\left(p \mid \omega_{t+1}, \cdot\right)$. For all other purposes, such as taking expectations across firms, the firm uses the correct period- $t$ employment distribution $\mathcal{N}\left(\cdot \mid \omega_{t}, N_{t-1}^{\star}\right)$ that occurs in each aggregate state.

The next step would be to compute recursively $\widetilde{\sigma}\left(p \mid \omega_{t}, \mathcal{N}\left(\cdot \mid \omega_{t-1}, N_{t-2}^{\star}\right)\right)$, a function of $p$, time $t, \omega_{t-1}$ and $\omega_{t}$. More generally, we can compute recursively the " $k^{t h}$-order" approximation

$$
\tilde{\sigma}\left(p \mid \omega_{t}, \mathcal{N}\left(\cdot \mid \omega_{t-1}, \mathcal{N}\left(\cdot \mid \omega_{t-2}, \cdots \mathcal{N}\left(\cdot \mid \omega_{t-k+1}, N_{t-k}^{\star}\right)\right)\right)\right)
$$

a function of $p$, time $t, \omega_{t-k+1}, \cdots, \omega_{t+1}$. Keeping track of the entire history, $k=\infty$, yields the exact optimal policy. Each time $k$ is increased by one, the dimension of the state space that one must keep track of is multiplied by the number of support points in the distribution of $\omega$ (the cardinality of $\Omega$ ). Hence, our algorithm sets $k=1$.

\section{B.5 Endogenous hiring}

We return to the full model, where hiring and sampling weights are endogenous. The algorithm for this case, which is how we obtain the results presented in the paper 18 is analogous

\footnotetext{
${ }^{18}$ The code is available from https://sites.google.com/site/fabienpostelvinay/working-papers
} 
to the case of exogenous sampling weights, but requires an additional iteration.

We start by guessing an arbitrary non-negative candidate profile of ad postings $\widetilde{a}_{t}^{(0)}(p, \omega)$ for $t=1,2, \cdots, T$ and $\omega \in \Omega$. Then at step $n=0,1,2, \cdots$ we proceed as follows. Given the current $\widetilde{a}_{t}^{(n)}(p, \omega)$ for $t=1,2, \cdots, T$ we evaluate $\widetilde{a}_{t}^{(n)}(p, \omega)$ at $\omega=\omega_{t}^{s}$ tar to obtain a path of sampling weights $\widetilde{a}_{t}^{(n)}\left(p, \omega_{t}^{\star}\right)$. Then, given an initial distribution of employment $N_{1}^{\star}(\cdot)$, we compute the resulting contact rates $\left(\lambda_{t}^{\star(n)}, \eta_{t}^{\star(n)}\right)$ and employment distributions $N_{t}^{\star(n)}(\cdot)$. We then apply the previous algorithm to obtain an estimated path $\widetilde{\sigma}^{(n)}\left(p \mid \omega_{t}, N_{t-1}^{\star(n)}\right)$. Next, we use the FOC (11) for optimal hiring: $c^{\prime}\left(H_{t}^{(n)}\left(p \mid \omega, N_{t-1}^{\star(n)}\right)\right)=\widetilde{\sigma}^{(n)}\left(p \mid \omega, N_{t-1}^{\star(n)}\right)$ to obtain an estimate of the hiring path $H_{t}^{(n)}\left(\cdot \mid \omega, N_{t-1}^{\star(n)}\right)$. Finally, we update the path of job ads to $\widetilde{a}_{t}^{(n+1)}(p, \omega)$ using $H_{t}^{(n)}\left(p \mid \omega, N_{t-1}^{\star(n)}\right)$ and the relationship between ads input and hiring output, with the contact rate and acceptance probability evaluated at the 'starred' RPE

$$
H_{t}^{(n)}\left(p \mid \omega, N_{t-1}^{\star(n)}\right)=\widetilde{a}_{t}^{(n+1)}(p, \omega) \eta_{t}^{\star(n)} P_{t}^{(n)}\left(p \mid \omega, N_{t-1}^{\star(n)}\right)
$$

where the probability that the offer is accepted in RPE can be computed beforehand, along with the turnover rates and employment distribution:

$$
P_{t}^{(n)}\left(p \mid \omega, N_{t-1}^{\star(n)}\right)=\frac{1-N_{t-1}^{\star(n)}(\bar{p})+s(1-\delta(\omega)) N_{t-1}^{\star(n)}(p)}{1-N_{t-1}^{\star(n)}(\bar{p})+s(1-\delta(\omega)) N_{t-1}^{\star(n)}(\bar{p})}
$$

We then raise $n$ by one, and iterate, until convergence at some $n^{\prime}$ of $\widetilde{a}_{t}^{(n)}(p, \omega)$ within some small tolerance for all $t, p$, and $\omega$. Then $\widetilde{a}_{t}^{n^{\prime}}\left(p, \omega_{t}^{\star}\right)$ provides an 'anticipatory' approximation to the true ad-posting function $a_{t}^{\star}(p)=a\left(p \mid \omega_{t}^{\star}, N_{t-1}^{\star}\right)$ in the same way that $\widetilde{\sigma}^{n^{\prime}}\left(p \mid \omega_{t}^{\star}, N_{t-1}^{\star}\right)$ approximates $\sigma_{t}^{\star}(p)$.

\section{B.6 Approximation diagnostics}

Our approximation to the RPE is predicated on the conjecture that $\sigma\left(p \mid \omega_{t+1}, \mathcal{N}\left(\cdot \mid \omega_{t}, N_{t-1}^{\star}\right)\right)$ is close to $\sigma\left(p \mid \omega_{t+1}, N_{t}^{\star}\right)=\sigma\left(p \mid \omega_{t+1}, \mathcal{N}\left(\cdot \mid \omega_{t}^{\star}, N_{t-1}^{\star}\right)\right)$ for every value of $\omega_{t}$ other than the $\omega_{t}^{\star}$ that occurs on the equilibrium path. This will be the case in particular if $N$ moves slowly over time and if $\sigma(p \mid \omega, N)$ is much less responsive to $N$ than it is to $\omega$.

After computing our proposed RPE, a natural candidate for the desired $\sigma\left(p \mid \omega_{t+1}, N_{t}\right)$ is $\sigma\left(p \mid \omega_{s}^{\star}, N_{s-1}^{\star}\right)$ for some time $s$, if any, when the state $\omega_{s}^{\star}=\omega_{t+1}$ and $N_{s-1}^{\star}$ is close to $N_{t}$ in the sup norm. We perform the following check on our candidate RPE. For every $t$, we select the time periods $s$ such that $\omega_{s}^{\star}=\omega_{t+1}$; with a state space $\Omega$ that takes 20 values, recurrence of $\omega$ is frequent and we can find many such times $s$. At each time $s$ in this set, we average $\sigma\left(p \mid \omega_{s}^{\star}, N_{s-1}^{\star}\right)$ over $p$ using the firm measure $\Gamma$. Finally, we study the time series variation of this average over the set of times $s$, and we find that it is minor, never 
exceeding $5 \%$ in relative terms, and often less. Conversely, the variation over times $s^{\prime}$ when $N_{s^{\prime}-1}^{\star}$ remains approximately the same, but $\omega_{s^{\prime}}^{\star}$ varies, can be as large as $70 \%$. Therefore in our approximate equilibrium, $\sigma\left(p \mid \omega_{t}^{\star}, N_{t-1}^{\star}\right)$ is much more sensitive to changes in its first argument, and indeed almost insensitive to changes in its second argument, conditional on the same value of the first. 